\title{
Applying the Super-EBM Model and Spatial Durbin Model to Examining Total Factor Ecological Efficiency From a Multi-Dimensional Perspective: Evidence From China
}

\section{Li Chengyu ( $\nabla$ woailaoer5555@outlook.com )}

Nanjing University of Aeronautics and Astronautics https://orcid.org/0000-0002-0798-2751

Zhang Yongmei

Shandong University of Science and Technology

Zhang Shiqiang

University of Jinan

Wang Jianmei

Shanghai University of Finance and Economics

\section{Research Article}

Keywords: total factor ecological efficiency, Super-EBM model, driving factors, Spatial durbin model

Posted Date: May 7th, 2021

DOl: https://doi.org/10.21203/rs.3.rs-396915/v1

License: (c) (i) This work is licensed under a Creative Commons Attribution 4.0 International License. Read Full License

Version of Record: A version of this preprint was published at Environmental Science and Pollution Research on August 7th, 2021. See the published version at https://doi.org/10.1007/s11356-021-15770w. 


\title{
1 Applying the Super-EBM model and Spatial Durbin
}

\section{China}

\section{model to examining total factor ecological efficiency} from a multi-dimensional perspective: Evidence from

\author{
Li Chengyu $^{1} \cdot$ Zhang Yongmei $^{2} \cdot$ Zhang Shiqiang $^{2,3} \cdot$ Wang Jianmei $^{4}$ \\ ${ }^{1}$ College of Economics and Management, Nanjing University of Aeronautics and Astronautics, Nanjing 21106, \\ China \\ ${ }^{2}$ College of Economics and Management, Shandong University of Science and Technology, Qingdao 266590, \\ China \\ ${ }^{3}$ University of Jinan ,Jinan250022,China \\ ${ }^{4}$ School of Public Economics and Administration, Shanghai University of Finance and Economics, Shanghai, \\ 200433, China
}

Correspondence should be addressed to woailaoer5555@outlook.com

\begin{abstract}
Ecological efficiency mainly emphasizes the importance of balancing the relationship between natural resources,energy,ecological environment and economic growth, which has aroused widespread concern in the
\end{abstract} world.China's rapid economic development has inevitably accompanied by serious resource exhaustion,environmental pollution and ecological deterioration in the past several decades, which has brought huge challenges to China's sustainable development.Therefore, establishing the evaluation framework of total-factor ecological efficiency (TFEE) and identifying its driving force has great significance for improving China's sustainable development capabilities.Firstly, a ecological efficiency evaluation framework is established based on the theory of total factor analysis.Secondly,establishing the Super-efficient hybrid distance model consider undesirable output,and measuring the total-factor ecological efficiency of nationwide,30 provinces and four regions during the period 2003-2017.Finally, the spatial effect of total-factor ecological efficiency and its driving factor are examined by using a Spatial Durbin model. The empirical results show that: (1)The efficiency measurement results show that the TFEE of China overall and regional showed different degrees of decline during the study period.There are significant differences among 30 provinces and four regions.Beijing,Tianjin,Shanghai are efficient,and the other provinces has not been effective.The TFEE of four region's are not achieve effective,and shows the distribution pattern of the eastern > northeast> central > western .(2)Moran's I index show that the TFEE in nationwide has a positive spatial autocorrelation,and showing a strong spatial agglomeration.However,the spatial distribution pattern of TFEE in China was unstable and easy to change;Moran scatter plot indicates that china's provincial TFEE has not only spatial dependence characteristics, but also spatial differences in spatial correlation.(3)Most factors are bound up with TFEE in various degree, in which, TP,JJ and HC play a positive in TFEE , and IS,CITY, and EI play a negative role in TFEE. Furthermore,ER show U type of relationship with TFEE.GDP and FDI cannot have a significant impact on TFEE at this stage.(4)The spatial Durbin model results show that TFEE has significant spatial spillover effect, and the improvement of the TFEE of province will increase 
the this TFEE of neighboring provinces.And spatial spillover effects of TP,IS,JJ,CITY,and HC are confirmed can significant impact the improvement of TFEE in neighboring provinces.

Keywords total factor ecological efficiency• Super-EBM model•driving factors;Spatial durbin model

\section{Introduction}

Since the implementation of the reform and opening policy,China's economic development has achieved many remarkable achievements (Tu et al., 2019).From 1978 to 2018, China's gross domestic product (GDP) grew at an average annual rate of $9.5 \%$.However, behind the rapid economic growth, there are also negative effects such as excessive consumption of natural resources and deterioration of the ecological environment.The development mode of "high pollution,high consumption,low efficiency" and high coal energy structure has caused resource crisis,and has aggravated environmental and ecological destruction (Dong et al. 2020). The problems of resources and ecological environment have severely restricted China's future sustainable development.Transforming the economic development approach,breaking the bottleneck restricting the sustainable development of China,supporting the economic development with less resources consumption,reducing environmental pollution becoming the focus of social concern.In order to clear these obstacles caused by environmental pollution and ecological deterioration,and explore the path of sustainable development,China government proposed to vigorously promote the construction of ecological civilization strategy.However, there are still difficult problems in handling the key to the coordination of ecological environment and economic development.How to realize the coordination between economic development, resource and energy consumption and environmental protection from a comprehensive perspective, instead of unilaterally solving one of these problems (Li et al.2016).Ecological efficiency(EE) is of increased importance in response to the challenges posed by those problems.

American scholars Schaltegger and Sturm first proposed the concept of ecological efficiency in 1990,and was used to measure the impact degree of environmental on economic activities (Schaltegger and Sturm. 1990).Since the concept of ecological efficiency was put forward,it has triggered a wave of research on it in the society.The WBCSD (World Business Council for Sustainable Development) expoundsecological efficiency as a business concept for the first time (WBCSD. 2000).BASE defines the concept of ecological efficiency from the perspective of products.The OECD expanded the concept to multiple fields such as governments, industrial enterprises , and defined ecological efficiency as the efficiency of using ecological environmental and natural resources to meet the demand of human activities (OECD. 1998).Mickwitz et al.(2006) pointed out that ecological efficiency involves multiple dimensions such as economy, society, ecological environment and can be used to effectively measure the level of sustainable development.Litos et al. (2017) defined ecological efficiency as a way to achieve optimal value at a lower cost.It can be seen that although there are certain differences in the definition of ecological efficiency from society, they all emphasize that ecological efficiency needs to take into account economic and ecological benefits, and maximize economic benefits while minimizing the impact of negative environmental externalities.

Ecological efficiency has been widely recognized and accepted by the academic, and has become an important tool for studying and analyzing the impact of economic activities on the environment.Currently,the scholars of ecological efficiency field have made great efforts to studied the evaluation system, evaluation methods 

the existing research progress,identifies the current challenges, and proposes an improved method from these three aspects.

Table 1 Literature for EE evaluation at the different dimensions

\begin{tabular}{|c|c|c|c|c|c|c|}
\hline Reference & Methods & Dimensions & Input & $\begin{array}{l}\text { Undesired } \\
\text { output }\end{array}$ & $\begin{array}{c}\text { Desirable } \\
\text { output }\end{array}$ & $\begin{array}{l}\text { Driving } \\
\text { factors }\end{array}$ \\
\hline $\begin{array}{l}\text { Long et al } \\
\text { (2015) }\end{array}$ & $\begin{array}{l}\text { DSBM and } \\
\text { Tobit model }\end{array}$ & $\begin{array}{l}\text { Industry } \\
\text { provincial } \\
\text { dimension }\end{array}$ & $\begin{array}{l}\text { Labor, capital, coal, } \\
\text { electricity and clinker }\end{array}$ & $\mathrm{CO}_{2}$ emission & $\begin{array}{c}\text { Cement } \\
\text { production }\end{array}$ & $\begin{array}{c}\text { cement industry value per } \\
\text { labor,wage welfare fee per } \\
\text { labor ,profit rate }\end{array}$ \\
\hline $\begin{array}{l}\text { Li et al } \\
(2018)\end{array}$ & $\begin{array}{l}\text { BCC and } \\
\text { spatial panel } \\
\text { econometric } \\
\text { model }\end{array}$ & $\begin{array}{l}\text { Industry } \\
\text { provincial } \\
\text { dimension }\end{array}$ & $\begin{array}{l}\text { Industrial energy land } \\
\text { area,water employees, } \\
\text { electric- } \\
\text { ity consumption, } \\
\text { industrial waste } \\
\text { emissions }\end{array}$ & & $\begin{array}{l}\text { Industrial } \\
\text { added value }\end{array}$ & $\begin{array}{l}\text { Economic development level, } \\
\text { industrial agglomeration,indus- } \\
\text { trial structure degree of opening } \\
\text { to the outside world, governme- } \\
\text { nt regulations, technological } \\
\text { progress and foreign investment } \\
\text { capital }\end{array}$ \\
\hline $\begin{array}{l}\text { Zhou et al } \\
\text { (2018) }\end{array}$ & $\begin{array}{l}\text { S-SBM } \\
\text { model } \\
\text { and panel } \\
\text { regression } \\
\text { models }\end{array}$ & $\begin{array}{c}\text { Cities } \\
\text { dimension }\end{array}$ & $\begin{array}{l}\text { The total quantity of } \\
\text { water supply, total } \\
\text { energy consumption, } \\
\text { and construction area }\end{array}$ & $\begin{array}{l}\text { Waste water, in- } \\
\text { dustrial soot, } \\
\text { industrial solid } \\
\text { wastes ,industrial } \\
\qquad \mathrm{SO}_{2}\end{array}$ & GDP & $\begin{array}{l}\text { Economic growth, industrial } \\
\text { structure, openness, technical } \\
\text { innovation, government regu- } \\
\text { lation,society,and land use inte- } \\
\text { nsity }\end{array}$ \\
\hline $\begin{array}{l}\text { Liu et al } \\
\text { (2020) }\end{array}$ & $\begin{array}{l}\text { Undesirable } \\
\text { output SBM } \\
\text { model and } \\
\text { spatial panel } \\
\text { econometric } \\
\text { model }\end{array}$ & $\begin{array}{c}\text { Cities } \\
\text { dimension }\end{array}$ & $\begin{array}{l}\text { Land area,employee } \\
\text { „Expenditure on } \\
\text { scientific under } \\
\text { takings,total fixed } \\
\text { asset investment }\end{array}$ & $\begin{array}{l}\text { Industrial waste- } \\
\text { water, industrial } \\
\mathrm{SO}_{2} \text {, industrial } \\
\text { smoke (powder) } \\
\text { dust }\end{array}$ & GDP & $\begin{array}{l}\text { Economic development level, } \\
\text { industrial structure, import and } \\
\text { export trade,infrastructure infor- } \\
\text { mation level local government } \\
\text { expenditure, social retail sales } \\
\text { of consumer goods }\end{array}$ \\
\hline $\begin{array}{l}\text { Liu et al } \\
\text { (2020) }\end{array}$ & $\begin{array}{l}\text { Super-SBM } \\
\text { model and } \\
\text { panel data } \\
\text { model }\end{array}$ & $\begin{array}{l}\text { Agricultural } \\
\text { provincial } \\
\text { dimension }\end{array}$ & $\begin{array}{l}\text { land, labor, capital, } \\
\text { and technologies }\end{array}$ & $\begin{array}{l}\text { chemical oxygen } \\
\text { demand,nitrogen } \\
\text { phosphorus }\end{array}$ & $\begin{array}{l}\text { Added value } \\
\text { of primary } \\
\text { industry }\end{array}$ & $\begin{array}{l}\text { Agricultural basic condition, } \\
\text { agricultural industrial structure } \\
\text { agricultural development poten- } \\
\text { tial agricultural input strength }\end{array}$ \\
\hline $\begin{array}{l}\text { Liu et al } \\
\text { (2020) }\end{array}$ & $\begin{array}{l}\text { Dynamic } \\
\text { network } \\
\text { DEA and } \\
\text { Tobit } \\
\text { regression }\end{array}$ & $\begin{array}{l}\text { Industry } \\
\text { setcor } \\
\text { dimension }\end{array}$ & $\begin{array}{l}\text { Industrial energy } \\
\text { consumption,indust- } \\
\text { rial employees, } \\
\text { industrial pollution } \\
\text { total investment }\end{array}$ & $\begin{array}{c}\text { Industrial } \mathrm{CO}_{2} \\
\text { emission }\end{array}$ & $\begin{array}{l}\text { Industrial } \\
\text { added value, } \\
\text { industrial } \\
\text { wastewater } \\
\text { treated, } \mathrm{SO}_{2} \\
\text { removed }\end{array}$ & $\begin{array}{c}\text { Industrial agglomeration, } \\
\text { industrial structure ,rationaliza- } \\
\text { tion economic growth, } \\
\text { technological progress, } \\
\text { foreign direct investment, } \\
\text { energy consumption structure }\end{array}$ \\
\hline
\end{tabular}

82 EE, the research of evaluation indicators has undergone a transformation from a single-factor framework to a

83 total-factor framework.In the single-single analysis framework, the ratio of economic development to

84 environmental impacts is often used to measure EE.Because,the high complexity of the natural resources,economy

85 and environment interaction, the analysis results obtained by the single-factor framework may cause distortions of 
reality and unable to provide the best choice for decision makers. To overcome the shortcomings of a single factor framework,many studies have tried to establish a total-factor analysis framework covering multiple input indicators, desirable output indicators and undesirable output indicators.Therefore, on the basis of referring to the existing research, an ecological efficiency evaluation index system based on the total factor framework is constructed, and names the efficiency value as Total-factor ecological efficiency(TFEE).

Second, to ensure that the measurement results are scientific and accurate,some scholars are trying to find a continuous improvement and appropriate EE evaluation method.At this stage, the mainstream evaluation methods of EE mainly include data envelopment analysis (DEA) (Storto 2016;Wang et al.2019; Mavi et al.2019;Storto 2020),stochastic frontier analysis (Moutinho et al. 2020),emergy analysis (Li et al.2011;Merlinab and Boileaua 2017),material flow analysis (Wang et al.2016; Wang et al. 2016),ecological footprint (Yang andYang 2019), and lifecycle assessment (Onat et al. 2019; Alizadeh et al. 2020).In these evaluation methods,DEA as a non-parametric calculation method that can simultaneously consider multiple outputs and multiple inputs, has been widely accepted by academia.The advantage of the DEA method is that it can avoid the influence of subjective factors on the weight during the measurement, so that the evaluation result of EE is more accurate.Because EE evaluation must consider not only desirable output but also undesirable output (e.g., environmental pollutants). Tone (2001) proposed slack-based measure model (SBM) model,and the model can simultaneously consider undesired output and slack variables, and can efficiently avoid redundancy and shortage problems.But the SBM model still exists the problem of potentially loses proportionality with the original inputs or outputs, thence Tone and Tsutsui (2010) proposed the epsilon-based measure model (EBM) and overcome those defects by a hybrid distance function. Besides, the value of $\mathrm{EE}$ often has multiple evaluation prone to equal to 1.This makes it impossible for us to effectively rank decision-making units(DMUs), nor can accurately reveal the heterogeneity between DMUs.Therefore, this article is based on the EBM model considering undesirable output, and then refers to Andersen and Petersen (1993) to extend it into a Super EBM (S-EBM) model.

Third, the research on the driving factors of EE has also received extensive attention by utilizing multitudinous econometric technology.According to previous research, it can be seen economic development level,industrial structure,technological progress,environmental regulations , and urbanization level are the most key driving factors of EE (Bai et al. 2018;Zhou et al. 2018). Traditional regression models have been widely used to examine the key driving factors of EE.In terms of measurement model selection,most studies have chosen to use Tobit regression (Long et al. 2015; Liu et al. 2017; Wu et al. 2018; Wang et al. 2018), quantile regression (Moutinho et al. 2018), and panel regression model (Zhao et al2018) to test the driving factors of EE.However, these regression models often overlook the ubiquitous spatial effects such as spatial dependence and spatial heterogeneity.According to the previous studies,spatial regression models are rarely used to study the driving factors of EE.This means that spatial spillovers embedded in EE and socioeconomic development of various regions are poorly understood. While the studies of driving factors about EE has garnered great attention internationally,a few studies have analyzes the driving factors and the spatial spillover effects behind EE by using the spatial regression model at China's provincial-level. Despite the great contributions of previous studies, only a few studies examined the relationship between anthropogenic factors and EE in neighboring regions and revealed the spatial spillover effects of EE. Therefore, the driving factors of EE need to be further studied. 

analysis framework,we establishing a total-factor ecological efficiency (TFEE) assessment indicator framework including inputs(energy consumption, natural resource consumption, labor, capital), desirable output(the gross domestic product), and undesirable output(CO2 ,SO2 ,waste water,solid wastes).Second,the Super-EBM considering undesirable outputs was firstly proposed for measuring China's China's (national-regional-provincial) three-dimensional TFEE from 2003 to 2017.Based on the evaluation results to explore the spatio-temporal dynamics of TFEE.Finally, this article's applied ESDA model and spatial regression model respectively to examine the spatial effect and driving forces of TFEE. Thus, it reveals both a spatio-temporal variation and a spatial correlation mechanism from different perspectives,so that offer to underpin practical implications for policymaking and multi-region coordination development.

\section{Study Area, data and variables}

\subsection{Study Area}

This article is based on 30 regions in China (22 provinces,four municipalities, and four autonomous regions from 2013 to 2017. The four regions of Tibet, Hong Kong, Macau and Taiwan are no longer within the scope of the study due to the difficulty of obtaining data.For the convenience of research, this article refers to these 30 regions collectively as provinces.Besides this article divides the 30 provinces into four regions according to China's economic regions, as shown in Figure 1.

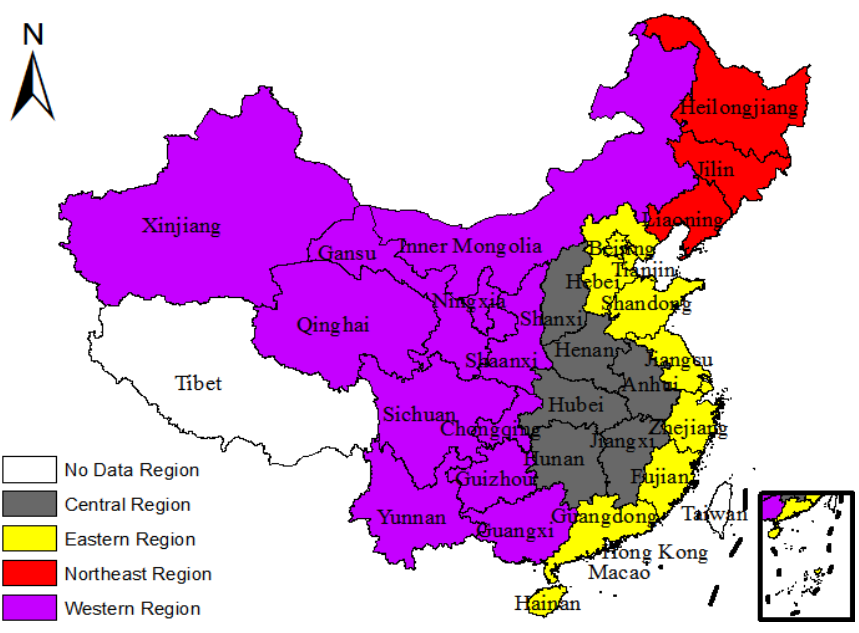

2.2. Data and variable description

The data required in this article mainly comes from the China Statistical Yearbook (2004-2018),China Energy Statistical Yearbook (2004-2018), and China Environment Yearbook (2004-2018). At the same time, the data is also revised in conjunction with relevant statistics of 30 provinces.In this study, the evaluate indicators of TFEE include input(ecological resource indicators), desirable output(economic indicators)and the undesirable output(environmental pollution indicators). The driving factors indicators of TFEE include nine variables:the level of economic 

regulation(GZ).All variables adopted in this paper are displayed in Table 2 and specific instructions are as follows:

Table 2 Variable description

\begin{tabular}{lll}
\hline Variable & Index & Unit \\
TFEE & Total factor Eco-Efficiency & \\
Energy & Energy Consumption & 10,000 tons of SCE \\
Capital & Capital Stock Based 2001 Year & 100 million yuan \\
Labour & Total Employment Population & 10,000 persons \\
Water & Total Water Consumption, & 100 million cubic meters \\
Land & Construction Land Area & 10000 Hectares \\
$\mathrm{GDP}$ & Gross National Product Based 2001 Year & 100 million yuan \\
$\mathrm{CO}_{2}$ & Carbon Dioxide Emissions & 10,000 tons \\
$\mathrm{SO}_{2}$ & Sulfur Dioxide Emissions & 10,000 tons \\
Waste Water & Waste Water Discharged & 10,000 tons \\
Solid Wastes & Industrial Solid Wastes Discharged & 10,000 tons \\
Economic Development & Real GDP Per Capita & 10,000 yuan \\
Industrial Structure & Secondary Industry Output Value/GDP & $\%$ \\
Energy Intensity & Energy Consumption/GDP & tone/10,000 yuan \\
Technological Progress & The Number of Patents Granted & 1 Pcs \\
Foreign Direct Investment & Actual Utilization of Foreign Capital & 100 million yuan \\
Industrial Agglomeration & Location Entropy & $\%$ \\
Environmental Regulation & Investment of Environmental Pollution Treatment & 100 million yuan \\
Urbanization & Proportion of Urban Population & $\%$ \\
Human Capital & Average Years of Education & years \\
\hline
\end{tabular}

(1)input indicators include energy consumption,total water consumption,construction land area,labor stock and capital stock.Energy consumption was directly obtained from the China Energy Statistics Yearbook.The labor,total water consumption and construction land area were directly obtained from China Statistical Yearbook (2004-2018),The capital stock was calculated by the"permanent inventory method" based on 2000 year (Zhang and Zhang 2003) .The formula is as follows: $K_{t}=I_{t}+\left(1-\delta_{t}\right) K_{t-1}$.

(2)Desirable output indicators include economic dimension indicators GDP.The GDP is calculated based on the statising 2004 year.

(3)Undesired output indicators include $\mathrm{CO}_{2}, \mathrm{SO}_{2}$,waste water, and industrial solid waste.The $\mathrm{CO}_{2}$ emission data directly from the CEADs database (Liu et al. 2015; Guan et al. 2012).Other undesired output data are obtained from the China Environmental Statistics Yearbook.

(4)The level of economic development(GDP) is represented by real gross domestic product per capita;the level of urbanization(CITY) is represented by proportion of urban population; industrial structure(IS) is represented by secondary industry output value/GDP; energy intensity(EI) is represented by energy consumption/GDP;technological progress(TP) is represented by the number of patents granted;foreign direct investment(FDI) is represented by actual utilization of foreign capital;environmental regulation(GZ) is represented by investment of environmental pollution treatment ;industrial agglomeration(IG)is represented by location entropy;human capital(HC) is represented by average years of education.

\section{Research method}


Data Envelopment Analysis (DEA), as a non-parametric analysis method, uses linear programming ideas to evaluate the relative effectiveness of comparable decision-making units.The DEA method was first introduced by American operations researcher Charnes and Cooper.Since the proposed method, it has been widely used in many fields and has become one of the most popular methods for evaluating relative efficiency (Charnes et al.1978).Generally, traditional DEA models are divided into two types: radial and non-radial.However, radial DEA models (such as CCR model) and non-radial DEA models (such as SBM model) have some drawbacks.For the radial DEA model, its main disadvantage is that it ignores non-radial slack when reporting efficiency scores( Avkiran et al. 2008). For the non-radial DEA model,its main disadvantage is that it the slacks potentially loses proportionality with the original inputs or outputs (Tone 2001).In view of the shortcomings of theradial DEA models and non-radial DEA models Tone and Tsutsui proposed an EBM model considering hybrid distance.The EBM model can not only overcome the primary defects of two type models measures,but also combine the advantages of two type models measures into a comprehensive framework and considering the undesirable output (Tone and Tsutsui 2010).Besides, because the value of efficiency often has multiple evaluation prone to equal to 1.This makes it impossible for us to effectively rank decision-making units(DMUs), nor to reveal the heterogeneity of DMUs.Therefore, we based on the EBM model that considers undesired output,and then extended to a form of Super-EBM (S-EBM) model by referring to Andersen and Petersen (Andersen and Petersen 1993).The model as shown in Eq. (1) the slack variables of desirable output $r$ and the slack variables of undesirable output $t ; b_{t j}$ stand for the $t$ th undesirable output of the $\mathrm{DMU}_{\mathrm{j}}$, and $p$ denotes the total number of undesirable outputs.

$$
\begin{aligned}
& \gamma^{*}=\min \frac{\theta-\varepsilon_{x} \sum_{i=1}^{m} \frac{\omega_{i}^{-} s_{i}^{-}}{x_{i k}}}{\rho+\varepsilon_{y} \sum_{r=1}^{q} \frac{\omega_{r}^{+} s_{r}^{+}}{y_{r k}}+\varepsilon_{b} \sum_{t=1}^{p} \frac{\omega_{t}^{b-} s_{t}^{b-}}{b_{t k}}} \\
& \text { s.t. } \sum_{j=1, j \neq k}^{n} x_{i j} \lambda_{j}+s_{i}^{-}=\theta x_{i k}, i=1, \ldots \ldots, m \\
& \sum_{j=1, j \neq k}^{n} y_{r j} \lambda_{j}-s_{r}^{+}=\varphi y_{r k}, r=1, \ldots \ldots, q \\
& \sum_{j=1, j \neq k}^{n} b_{t j} \lambda{ }_{j}+s_{p}^{b-}=\varphi b_{t k}, t=1, \ldots \ldots, p \\
& \lambda \geq O, s^{-} \geq 0, s^{+} \geq 0, s^{b} \geq 0
\end{aligned}
$$

\subsection{Spatial econometric analysis methods}

Spatial econometric analysis is usually divided into two steps.In the first step, a spatial autocorrelation test is used to test whether there is spatial correlation among dependent variables because spatial econometric analysis is needed only when the exists of spatial autocorrelations.Geoda 1.6 is used for analysis(see Section 3.2.1). The first step is to test whether there is a spatial correlation between the dependent variables through the spatial autocorrelation test,because the existence of spatial autocorrelation is a prerequisite for spatial econometric analysis. Geoda 1.6 is used for analysis (see section 3.2.1).In the second step, according to the spatial autocorrelation, appropriate spatial econometric model should be chosen to examine the relationship between the 


\subsubsection{Spatial autocorrelation test}

This article first uses the global Moran's I index to test the spatial autocorrelation of TFEE in 30 provinces , as shown in Eq. (2)

$$
\text { Moran's I }=\frac{\sum_{\mathrm{i}=1}^{\mathrm{n}} \sum_{\mathrm{j}=1}^{\mathrm{n}} \mathrm{W}_{\mathrm{ij}}\left(\mathrm{Z}_{\mathrm{i}}-\overline{\mathrm{Z}}\right)\left(\mathrm{Z}_{\mathrm{j}}-\overline{\mathrm{Z}}\right)}{S^{2} \sum_{i=1}^{n} \sum_{j=1}^{n} \mathrm{~W}_{\mathrm{ij}}}
$$

In the formula (2), $\mathrm{n}$ is the number of research objectives, $\mathrm{Zi}$ and $\mathrm{Zj}$ are observations of the $\mathrm{i}$ and $\mathrm{j}$ regions, $\mathrm{Wij}$ stand for the spatial weight matrix,S2 is the observed variance, $\bar{Z}$ is the average of the observations.The Moran's I index range is $[-1,1]$, the closer to 1 or -1 , the stronger the spatial correlation.If the Moran's I index is positive, it indicates that agglomeration is present. If the Moran's I index is negative, it indicates that the representation is spatially different. When Moran's I index is close to 0 , it indicates that the spatial distribution is random and no spatial correlation.

To ensure the robustness of the empirical test results, this article simultaneously construct 0-1 spatial weights matrix and the geographical distance spatial weight matrix.For the convenience of research, the two spatial weight matrices are abbreviated as $\mathrm{W} 1$ matrix and $\mathrm{W} 2$ matrix.

The 0-1 spatial weight matrix mainly examines the adjacent relationship between spatial units. The definition of the element value is: adjacent to 1 , non-adjacent to 0 ,details as follows:

$$
W_{i j}=\left\{\begin{array}{l}
1, \text { When spatial unit } i \text { is adjacent to spatial unit } j \\
0, \text { When spatial unit } i \text { and spatial unit } j \text { are not adjacent }
\end{array}\right.
$$

This article chooses the first-order Rook adjacent to construct the 0-1 spatial weight matrix (W1). Since Hainan Province is not adjacent to other provinces and cities, it is an isolated island unit, which will make the spatial weights unable to be standardized. Therefore, considering Hainan and Guangdong Provinces The neighbors are relatively close and originally separated from Guangdong Province, so Hainan Province and Guangdong Province are artificially assumed to be adjacent.

Based on the 0-1 space weight, the spatial interaction and dependence between adjacent regions are simple treated as homogeneous, ignoring the spatial interaction and dependence of the region may not be exactly the same.In view of this, this paper uses geographic distance to construct the geographic distance spatial weight matrix (W2), and the specific formula is shown in Eq (4).

$$
W_{i j}=\left\{\begin{array}{l}
0, i=j \\
1, i=d_{i j}^{2}, i \neq j^{(4)}
\end{array}\right.
$$

Among them, $d_{i j}$ represents the geographic distance between area $\mathrm{i}$ and area $\mathrm{j}$, where the distance is Euclidean distance. Because the latitude and longitude of a spatial unit can more accurately reflect the location of the spatial unit, this paper calculates the Euclidean distance of geographic distance in a two-dimensional space based on the geographic coordinates converted from latitude and longitude.

\subsubsection{Spatial econometric models}

The spatial econometric model can effectively solve the spatial dependence and correlation between the variables being investigated. Traditional spatial econometric models are divided into two types: one is the spatial 
lag model(SLM), the other is the spatial error model(SEM) (Anselin et al.2004).

The SLM can be expressed as:

$$
y_{i t}=\rho \sum_{j=1}^{N} w_{i j} y_{i t}+X_{i t} \beta+\varepsilon_{i t}(5)
$$

In the formula (5), $y$ represents dependent variable; $X$ represents explanatory variables; $W$ represents the spatial weight matrix; $\varepsilon$ is a random error term; $\rho$ is the spatial regression coefficient; $\beta$ is a estimated independent coefficient.

The SEM can be expressed as:

$$
\begin{aligned}
& y_{i t}=X_{i t} \beta+\varepsilon_{i t} \\
& \varepsilon=\lambda W \varepsilon_{i t}+v_{i t}
\end{aligned}
$$

In the formula (6), $y$ represents dependent variable; $X$ represents explanatory variables; $W$ represents the spatial weight matrix; $\varepsilon$ is a random error term; $\lambda$ is the spatial autocorrelation coefficient; $\beta$ is a estimated independent coefficient; $v$ is a disturbance terms.

In 2009, Pace and Lesage introduced an equation containing a spatial lag term, including dependent and independent variables (Pace and Lesage 2009). This equation can effectively realize the complementary advantages of SLM and SEM, and is named SDM

The SDM can be expressed as:

$$
y_{i t}=\rho W y_{i t}+X_{i t} \beta+W X_{i t} \theta+\varepsilon_{i t} \text { (7) }
$$

In the formula (7), $y$ represents dependent variable; $X$ represents explanatory variables; $W$ represents the spatial weight matrix; $\varepsilon$ is a random error term; $\rho$ is the spatial regression coefficient; $\beta$ is a estimated independent coefficient; $\theta$ represents the spatial lag coefficient of the independent variable to be estimated.

\section{Empirical Analysis and Results}

\subsection{TFEE results analysis}

According to the Eq (1),we estimated the TFEE for national, regional and provincial dimensions during the period of 2003-2017.The measurement results are displayed in Figure 2,Table 3 and Table 4.

\subsubsection{National perspective}

From a national perspective,the China's TFEE is relatively high and the 15 -year means is 0.6879 .From 2003 to 2017, the TFEE remained at the second highest level of 0.6000 to 0.8000 .However, China's overall TFEE showed a downward trend during 2003-2017, and the average annual growth rate was $-1.37 \%$.The TFEE fell from 0.7506 in 2003 to 0.6106 in 2017, and the downward trend from 2003 to 2017 was relatively strong. Among them the downward trend from 2003 to 2010 was relatively stable, and the downward trend from 2010 to 2017 was relatively sharp.Since the new century, China's economy has shown a trend of rapid growth, the people's living standards have been continuously improved, and TFEE has also been developed.But at the same time, the negative impact accumulated by China's past extensive development model of "three highs"(high investment, high consumption and high pollution) has also begun to intensively erupt.Ecological destruction, environmental 

improvement of TFEE.Therefore,the current level of China's TFEE is relatively high, but it is showing a downward trend.

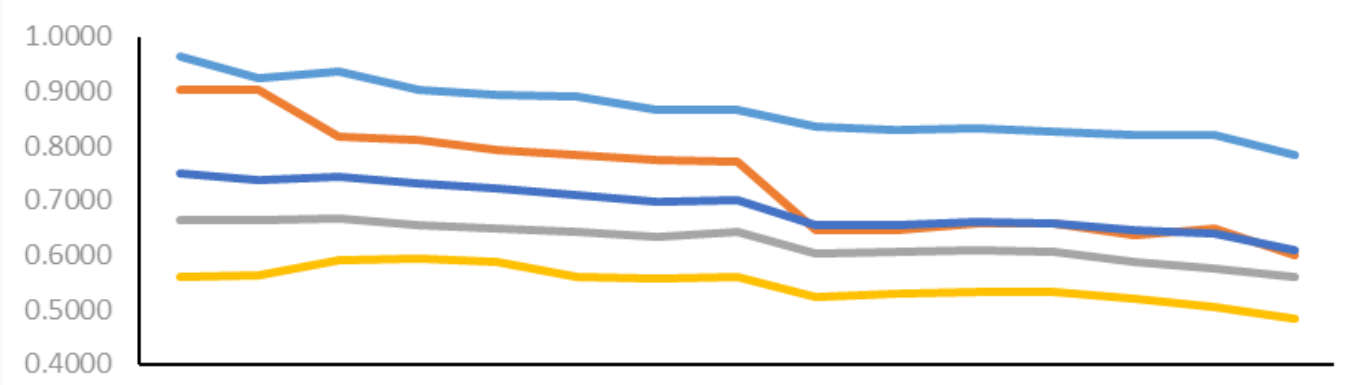

200320042005200620072008200920102011201220132014201520162017

291

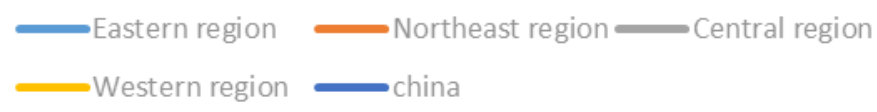

Figure 2.Development Trend of TFEE in China and the four Regions (2003-2017)

\subsubsection{Regional perspective}

From a regional perspective, the TFEE of eastern region is the highest, the 15 -year means reached 0.8664 , which is much higher than the other three regions and the national means. The TFEE basically remained at a high level above 0.8000 during the study period.The TFEE of the northeast region is the second, the 15-year means reached 0.7369 , which is higher than the other two regions and the national means. The TFEE varies greatly and is not stable enough during the study period. The TFEE of the central region is the third, the 15-year means reached 0.6245 , which is lower than the national means. The TFEE remain between 0.5500-0.6600 during the study period.The TFEE of western region is the lowest, with a 15 -year means only reached 0.5469 , which is lower than the national means. The TFEE is lower than 0.6000 during the study period.Simultaneously, the TFEE of the four regions showed a downward trend during 2003-2017.Among them, the downward trend of northeast region is the most intense, and the average annual growth rate was $-2.70 \%$. The downward trend of eastern region is the most gentle, and the average annual growth rate was $-0.89 \%$. The downward trend of central and western regions is basically consistent with the national downward trend, with average annual growth rates of $-1.14 \%$ and $-1.37 \%$, respectively.

It can be seen that the TFEE of the four regions have not been achieve effective, and there are obvious differences between regions, showing an arrangement pattern of eastern region> northeast region> central region> western region.The eastern and northeastern regions have superior geographical location and have always been the economic development center of China.It has strong capital, technology, and talent advantages, making its TFEE always a leader in the China.However, with the implementation of development strategies such as "Rise of Central China"、"Development of The Western Region"、"Belt and Road",the westward shift of the economic center of gravity, and the decline in the capacity of the ecological environment due to regional economic growth.The TFEE of eastern and northeastern regions shows a downward trend.As the economic development transition region of China,the central region has abundant natural resources, but its economic foundation and scale are far inferior to the eastern and northeastern regions. Its resource utilization efficiency and capital conversion rate are low, and its policy advantages are not obvious, making its TFEE relatively low.The western region is restricted by 

the ecological environment carrying capacity is low, so the TFEE is the lowest.

Table 3.TFEE calculation results of the four regions (2003-2017)

\begin{tabular}{lllllllllll}
\hline Region & 2003 & 2005 & 2007 & 2009 & 2011 & 2013 & 2015 & 2017 & Mean & Rankin \\
\hline Eastern region & 0.9654 & 0.9356 & 0.8929 & 0.8669 & 0.8345 & 0.8331 & 0.8192 & 0.7839 & 0.8664 & 1 \\
Northeast region & 0.9034 & 0.8168 & 0.7945 & 0.7755 & 0.6463 & 0.6575 & 0.6359 & 0.5988 & 0.7369 & 2 \\
Central region & 0.6651 & 0.6668 & 0.6488 & 0.6326 & 0.6031 & 0.6086 & 0.5873 & 0.5601 & 0.6245 & 3 \\
Western region & 0.5604 & 0.5912 & 0.5889 & 0.5578 & 0.5234 & 0.5327 & 0.5203 & 0.4839 & 0.5469 & 4 \\
\hline
\end{tabular}

\subsubsection{Provincial perspective}

From a provincial perspective, The TFEE means of Beijing, Shanghai and Tianjin are 1.0365, 1.0275 and 1.0121 respectively,and its TFEE were also greater than 1 during 2003 to 2017.The TFEE of these three provinces achieve effective.It shows that the TFEE of these provinces is above the frontier, both input and output reach the best configuration.The TFEE of Guangdong is basically effective. Its TFEE means is 0.9976, and the TFEE greater than 1 during 2003 to 2016, but it was not effective in 2017. It shows that Guangdong's input and output are close to the effective state.Although the gap of input and output is very small,the stability is not high enough.For TFEE of Guangdong province, there is still a lot of room for improvement.The provinces with relatively high TFEE are Heilongjiang, Zhejiang, Fujian, Hainan, Shandong, Jiangsu, Liaoning and Inner Mongolia. The means of TFEE is above 0.7000, which is higher than the national means.Among them, the TFEE of Heilongjiang, Fujian, Hainan, Liaoning, Inner Mongolia, and Shandong canachieve effective in a few or individual years.The TFEE of Zhejiang and Jiangsu is relatively stable, maintaining between $0.7000-0.9000$.It shows that although these provinces's input and output are ineffective state, the gap of input and output is relatively small and there is relatively large room for improvement.The TFEE means in the other 18 provinces is lower than the national means.Among them, The TFEE means of Hebei, Anhui, Sichuan, Hunan, Jilin, Hubei, Henan, Jiangxi, Shanxi, and Chongqing higher than 0.6000. It shows that these provinces's input and output are ineffective state, and the gap of input and output is relatively large, and it is relatively limited room for improvement.The TFEE means of Shaanxi, Gansu, Yunnan, Guangxi, and Xinjiang is less than 0.6000, and the TFEE means of Guizhou, Qinghai, and Ningxia is less than 0.5000.It shows that these provinces's input and output are ineffective state,and the gap of input and output is extremely large,making it grear difficult to improvement.It can be seen that there are significant differences in the TFEE of

34130 provinces in China.There are 12 provinces with high TFEE, accounting for $40 \%$. These provinces are mainly 342 distributed in the eastern and northeast regions.There are 18 provinces with low TFEE, accounting for $60 \%$. These provinces are mainly distributed in the central and western regions.

From the perspective of development trend,due to the overall environmental impact of China's development, the development trend of most provinces is similar to that of China as a whole, showing a downward trend.

Specifically, Chongqing, Inner Mongolia, Sichuan, and Tianjin showed a growing trend, its proportion is $13.33 \%$. The four provinces's growing trend are relatively flat, with an average annual growth rate of only $0.53 \%$,

$3480.39 \%, 0.18 \%$ and $0.05 \%$. The other 26 provinces 's average annual growth rate are negative, showing a downward 349 trend, accounting for 86.66\%.Hainan, Hebei, Liaoning, Heilongjiang, Fujian, Shandong, and Guangdong have a 350 sharp downward trend. The average annual growth rate of Shandong and Guangdong are about $-1.5 \%$, and the 351 average annual growth rate of other 5 provinces higher than $-2.5 \%$; The downward trend in Jilin, Shanxi, Shaanxi,

352 Henan, Guangxi, and Yunnan is more obvious, and the average annual growth rate of these provinces higher than 
354 the overall downward trend in China.It can be seen that the provinces with high TFEE have an unstable stable 355 development trend,and the average annual growth rate is relatively low,and they are mainly concentrated in the 356 northeast and east regions. The provinces with low TFEE have a relatively stable development trend and a high 357 average annual growth rate, and they are mainly concentrated in the central and western regions.

Table 4.TFEE calculation results of the 30 provinces (2003-2017)

\begin{tabular}{|c|c|c|c|c|c|c|c|c|c|c|}
\hline Province & 2003 & 2005 & 2007 & 2009 & 2011 & 2013 & 2015 & 2017 & Mean & Ranking \\
\hline Beijing & 1.0351 & 1.0311 & 1.0331 & 1.0502 & 1.0427 & 1.0356 & 1.0326 & 1.0328 & 1.0365 & 1 \\
\hline Shanghai & 1.0305 & 1.0248 & 1.0247 & 1.0365 & 1.0342 & 1.0279 & 1.0217 & 1.0226 & 1.0275 & 2 \\
\hline Tianjin & 1.0031 & 1.0025 & 1.0023 & 1.0243 & 1.0262 & 1.0163 & 1.0158 & 1.0103 & 1.0121 & 3 \\
\hline Guangdong & 1.0187 & 1.0159 & 1.0127 & 1.0176 & 1.0125 & 1.0050 & 1.0010 & 0.8087 & 0.9976 & 4 \\
\hline Heilongjiang & 1.0049 & 1.0057 & 1.0052 & 1.0061 & 0.6986 & 0.6927 & 0.6768 & 0.6347 & 0.8535 & 5 \\
\hline Zhejiang & 0.8678 & 0.8366 & 0.8136 & 0.8102 & 0.7795 & 0.7999 & 0.7858 & 0.7579 & 0.8080 & 6 \\
\hline Fujian & 1.0014 & 0.8245 & 0.8067 & 0.7786 & 0.7302 & 0.7402 & 0.7132 & 0.6773 & 0.7899 & 7 \\
\hline Hainan & 1.0224 & 1.0188 & 1.0032 & 0.7583 & 0.6773 & 0.6278 & 0.5743 & 0.5196 & 0.7860 & 8 \\
\hline Shandong & 0.8820 & 1.0014 & 0.7575 & 0.7335 & 0.6914 & 0.7153 & 0.6969 & 0.6936 & 0.7622 & 9 \\
\hline Jiangsu & 0.7914 & 0.7494 & 0.7587 & 0.7868 & 0.7364 & 0.7523 & 0.7506 & 0.7206 & 0.7572 & 10 \\
\hline Liaoning & 1.0016 & 0.7497 & 0.7198 & 0.7161 & 0.6715 & 0.6778 & 0.6467 & 0.6090 & 0.7301 & 11 \\
\hline Inner Mongolia & 0.5952 & 1.0004 & 1.0028 & 0.6767 & 0.6049 & 0.6266 & 0.6450 & 0.6307 & 0.7125 & 12 \\
\hline Heibei & 1.0011 & 0.8506 & 0.7169 & 0.6729 & 0.6144 & 0.6102 & 0.6002 & 0.5952 & 0.6874 & 13 \\
\hline Anhui & 0.6860 & 0.6900 & 0.6657 & 0.6626 & 0.6347 & 0.6587 & 0.6352 & 0.5971 & 0.6579 & 14 \\
\hline Sichuan & 0.6220 & 0.6307 & 0.6422 & 0.6510 & 0.6671 & 0.6913 & 0.6709 & 0.6390 & 0.6545 & 15 \\
\hline Hunan & 0.6778 & 0.6561 & 0.6461 & 0.6560 & 0.6422 & 0.6505 & 0.6320 & 0.6043 & 0.6487 & 16 \\
\hline Jilin & 0.7037 & 0.6950 & 0.6585 & 0.6044 & 0.5687 & 0.6019 & 0.5842 & 0.5529 & 0.6271 & 17 \\
\hline Hubei & 0.6365 & 0.6209 & 0.6288 & 0.6361 & 0.6242 & 0.6345 & 0.6049 & 0.5675 & 0.6218 & 18 \\
\hline Henan & 0.7188 & 0.7221 & 0.6825 & 0.6259 & 0.5655 & 0.5408 & 0.5216 & 0.5027 & 0.6131 & 19 \\
\hline Jiangxi & 0.6071 & 0.6122 & 0.5850 & 0.5994 & 0.5881 & 0.6139 & 0.6174 & 0.5904 & 0.6032 & 20 \\
\hline Shanxi & 0.6644 & 0.6994 & 0.6846 & 0.6158 & 0.5638 & 0.5529 & 0.5130 & 0.4983 & 0.6027 & 21 \\
\hline Chongqing & 0.5893 & 0.5580 & 0.5521 & 0.5746 & 0.6037 & 0.6466 & 0.6455 & 0.6375 & 0.6011 & 22 \\
\hline Shaanxi & 0.6336 & 0.6277 & 0.6134 & 0.6075 & 0.5673 & 0.5785 & 0.5431 & 0.5074 & 0.5904 & 23 \\
\hline Gansu & 0.5587 & 0.6019 & 0.5992 & 0.5914 & 0.5385 & 0.5617 & 0.5607 & 0.5106 & 0.5703 & 24 \\
\hline Yunnan & 0.6596 & 0.6433 & 0.6273 & 0.6306 & 0.5233 & 0.5101 & 0.4639 & 0.4191 & 0.5642 & 25 \\
\hline Guangxi & 0.6411 & 0.6250 & 0.5990 & 0.5577 & 0.5038 & 0.4970 & 0.4836 & 0.4640 & 0.5470 & 26 \\
\hline Xingjiang & 0.5401 & 0.5357 & 0.5275 & 0.5232 & 0.4836 & 0.4707 & 0.4731 & 0.4161 & 0.5004 & 27 \\
\hline Guizhou & 0.4814 & 0.5055 & 0.5295 & 0.5351 & 0.5001 & 0.5021 & 0.4642 & 0.4184 & 0.4966 & 28 \\
\hline Qinghai & 0.4595 & 0.4214 & 0.4323 & 0.4415 & 0.4305 & 0.4356 & 0.4176 & 0.3547 & 0.4275 & 29 \\
\hline Ningxia & 0.3835 & 0.3533 & 0.3522 & 0.3464 & 0.3343 & 0.3393 & 0.3556 & 0.3250 & 0.3506 & 30 \\
\hline Mean & 0.7506 & 0.7437 & 0.7228 & 0.6976 & 0.6553 & 0.6605 & 0.6449 & 0.6106 & 0.6879 & \\
\hline
\end{tabular}

\subsection{Spatial autocorrelation of TFEE}

According to the TFEE of 30 province from 2013 to 2017, under the W1 matrix(0-1 distance) and W2 matrix(geographical distance), use GeoDa1.6 software to estimate the Moran's I index (Table 5), and draw its development trend chart (Figure 3).It can be seen from Table 5 that the global Moran's I index of TFEE based on the W1matrix and W2 matrix was positive, showing a high degree of consistency during the study period .Under

364 the W1 matrix ,the range of the global Moran's I index is between 0.306-0.512, and all years have passed the $1 \%$

365 significance level test and and the significance is positive.Under the W2 matrix, the global Moran's I index ranges

366 from 0.2470 to 0.3850 . Like the $\mathrm{W} 1$ matrix, all years passed the $1 \%$ significance level test, and the significance is

367 positive.The results show that the TFEE of China has a significant positive spatial autocorrelation, and high (low) 
adjacent provincial units are relatively agglomerated, showing a strong spatial agglomeration pattern.

Table 5.Result of spatial autocorrelation test (Moran's I index).

\begin{tabular}{llccccc}
\hline Year & Moran's I & $\mathrm{Z}$ & $\mathrm{P}$ & Moran's I & $\mathrm{Z}$ & $\mathrm{P}$ \\
\hline & & $\mathrm{W} 1$ & & $\mathrm{~W} 2$ & \\
2003 & 0.5120 & 4.3710 & $0.0000^{* * *}$ & 0.2930 & 3.4570 & $0.0010^{* * *}$ \\
2004 & 0.4210 & 3.6570 & $0.0000^{* * *}$ & 0.2970 & 3.5160 & $0.0000^{* * *}$ \\
2005 & 0.4190 & 3.6440 & $0.0000^{* * *}$ & 0.2880 & 3.4220 & $0.0010^{* * *}$ \\
2006 & 0.3880 & 3.4080 & $0.0010^{* * *}$ & 0.2680 & 3.2220 & $0.0010^{* * *}$ \\
2007 & 0.3680 & 3.2490 & $0.0010^{* * *}$ & 0.2470 & 3.0010 & $0.0030^{* * * *}$ \\
2008 & 0.4180 & 3.6690 & $0.0000^{* * *}$ & 0.2630 & 3.1930 & $0.0010^{* * * *}$ \\
2009 & 0.3310 & 2.9880 & $0.0030^{* * *}$ & 0.2740 & 3.3290 & $0.0010^{* * *}$ \\
2010 & 0.3220 & 2.9030 & $0.0040^{* * *}$ & 0.2540 & 3.1080 & $0.0020^{* * *}$ \\
2011 & 0.3610 & 3.2750 & $0.0010^{* * *}$ & 0.3260 & 3.9470 & $0.0000^{* * * *}$ \\
2012 & 0.3300 & 3.0100 & $0.0030^{* * *}$ & 0.3230 & 3.9010 & $0.0000^{* * * *}$ \\
2013 & 0.3310 & 3.0110 & $0.0030^{* * *}$ & 0.3230 & 3.8910 & $0.0000^{* * *}$ \\
2014 & 0.3060 & 2.8050 & $0.0050^{* * *}$ & 0.3170 & 3.8290 & $0.0000^{* * *}$ \\
2015 & 0.3170 & 2.8970 & $0.0040^{* * *}$ & 0.3210 & 3.8650 & $0.0000^{* * *}$ \\
2016 & 0.3890 & 3.5050 & $0.0000^{* * *}$ & 0.3850 & 4.5920 & $0.0000^{* * *}$ \\
2017 & 0.4120 & 3.6420 & $0.0000^{* * * *}$ & 0.3280 & 3.9070 & $0.0000^{* * * *}$ \\
\hline
\end{tabular}

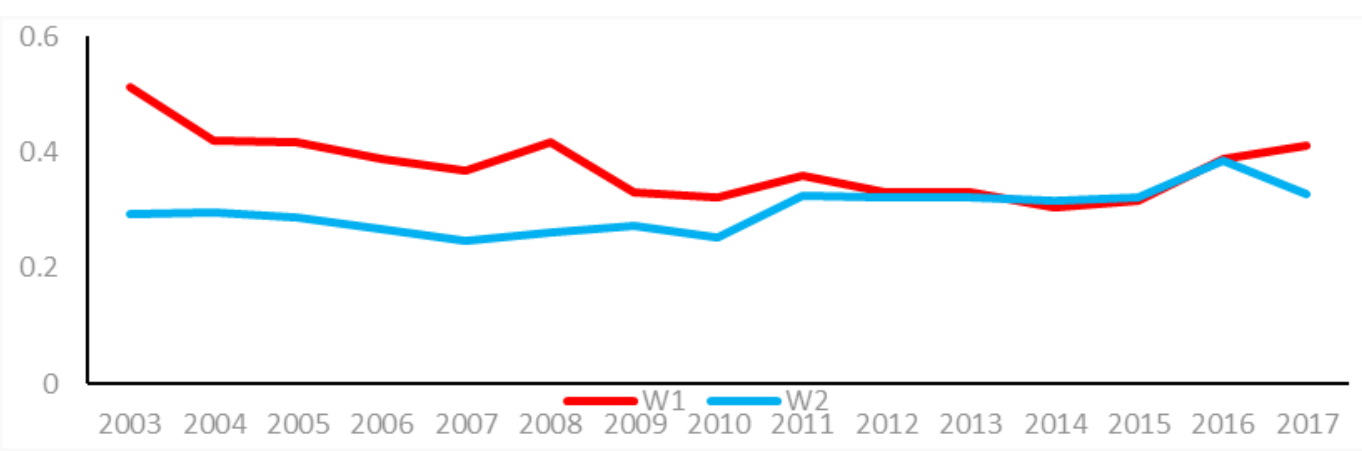

Figure 3. Development trend of Moran's I index (2003-2017)

It can be seen from Figure 3 that the global Moran's I index under the W1 matrix and W2 matrix shows different development trends.Under the W1 matrix, the global Moran's I index shows a downward trend, and the dynamics of up and down waves are obvious, and the fluctuation frequency is high.There was a relatively drastic downward trend from 2003 to 2007, and a downward trend from 2008 to 2014, which fell to the lowest point in 2014. After 2014, the development trend rebounded, showing a relatively stable upward trend.Under the W2 matrix,the global Moran's I index shows a steady upward trend.From 2003 to 2007, it showed a weak downward trend, and fell to the lowest point in 2007, and then began to rebound, showing a significant upward trend.The results show that although China's TFEE is spatially significant, the degree of prominence of its agglomeration situation will vary due to the difference of the spatial matrix.The wave dynamics of the global Moran's I index shows that the spatial distribution pattern of China's TFEE is unstable and easy to change.

Although the Moran's I index can scientifically reflect the spatial autocorrelation of TFEE,its has a certain limitation. When some provinces show positive spatial autocorrelation and others some provinces show negative spatial autocorrelation,these effects of the two types provinces will offset each other,in which case the Moran's I index may tend to 0 and show non-spatial autocorrelation. Therefore, in order to more scientifically and accurately reflect the spatial characteristics and agglomeration of TFEE. We are based on Moran's I scatter plot and visualize it using ArcGIS software.We choose three representative years (2003, 2010, and 2017) to visualize the Moran's I scatter plots of TFEE, which are summarized in Figure 4. 

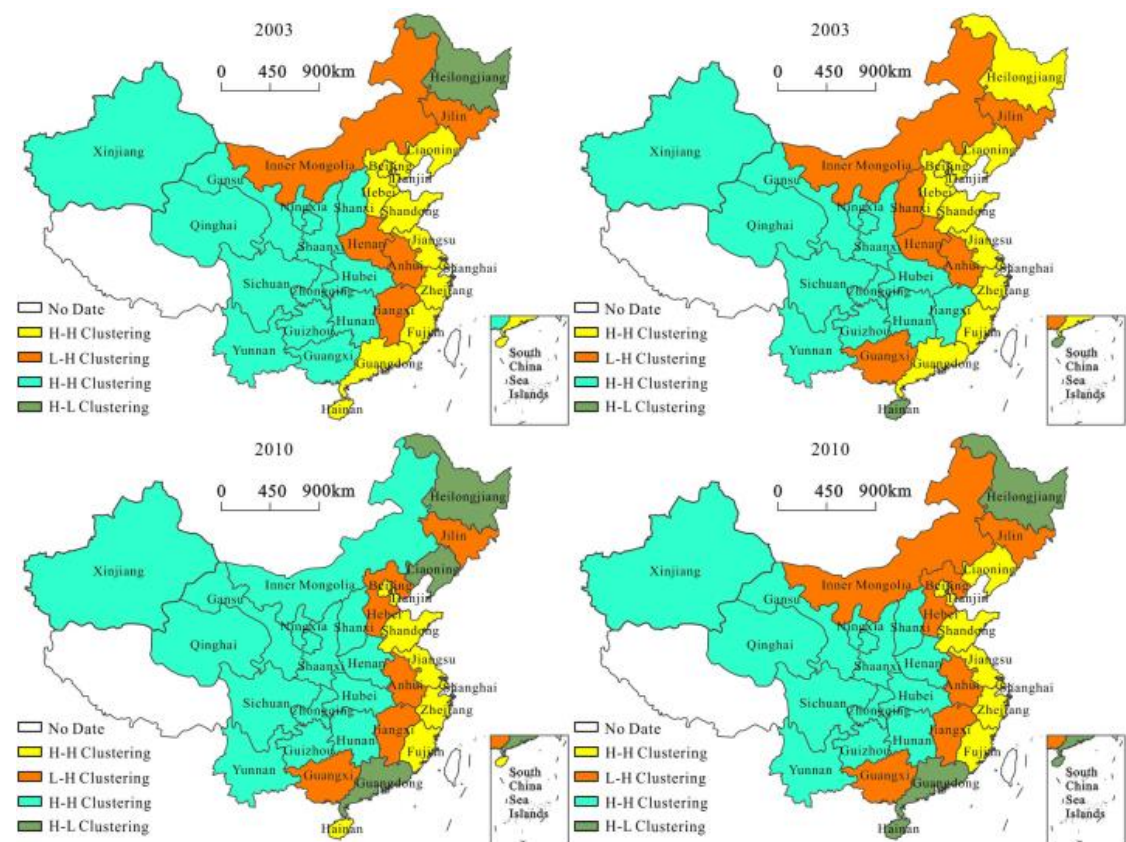

H-LClustering 2010

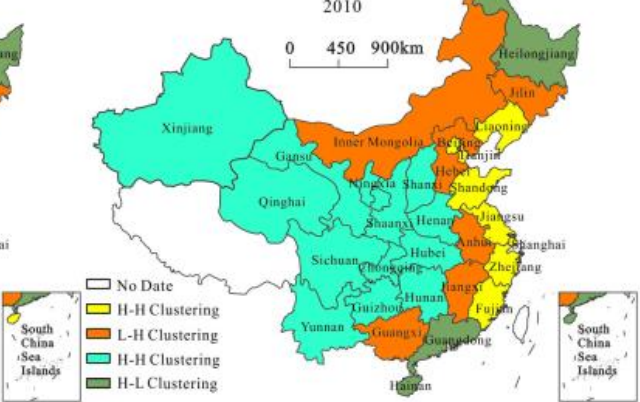

2017

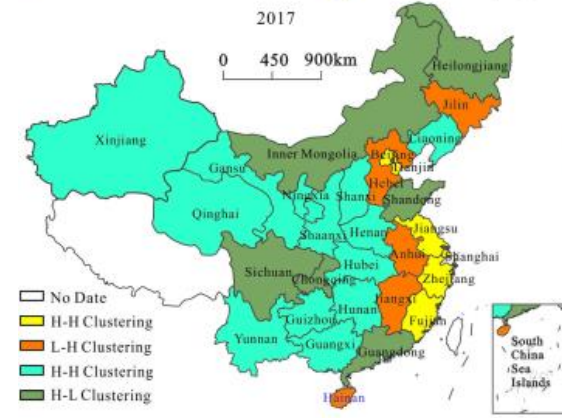

W1

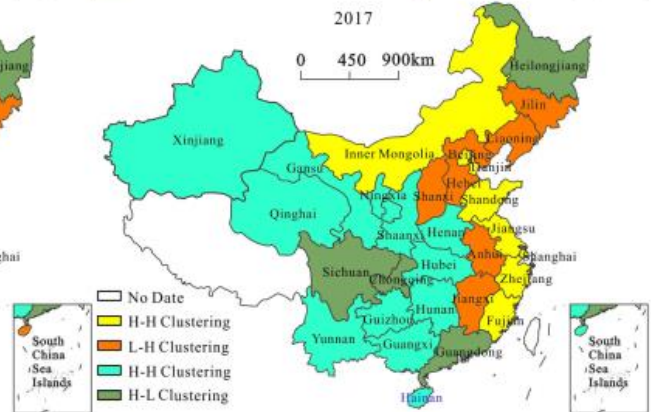

W2

Figure 4. Chinese provincial TFEE Moran's I spatial distribution of scatter

As shown in Figure 4, under the two spatial weight matrices, most provinces show H-H and L-L clusters, and show positive spatial autocorrelation.Under the W1 matrix,there are 24 provinces (80\%), 22 provinces (73.33\%), and 19 provinces (63.33\%) located in the first and third quadrants in 2003,2010, and 2017.Under the W2 matrix,there are 23 provinces $(76.66 \%), 21$ provinces $(70 \%)$, and 20 provinces $(66.66 \%)$ located in the first and third quadrants in 2003,2010, and 2017.

Specifically, under the two spatial weight matrices, the provinces that are located in the first quadrant and show the $\mathrm{H}-\mathrm{H}$ agglomeration pattern are mainly distributed in the eastern coastal area in a belt shape. With the passage of time, the number of provinces in this quadran has decreased.Beijing, Shanghai,Tianjin, Zhejiang,Jiangsu,and Fujian are the most stable and they are all in the first quadrant from 2003 to 2017.Other provinces have entered other quadrants over time. For example, Guangdong and Hebei entered the second and fourth quadrants in 2010, and Shandong entered the fourth quadrant in 2017.There are many provinces in the third quadrant, mainly concentrated in the western region,and their distribution is relatively stable.Qinghai, Hubei, Shaanxi,Hunan, Gansu, Yunnan, Guizhou, Ningxia, and Xinjiang are the most stable, and and they are all in the third quadrant from 2003 to 2017. Other provinces have entered other quadrants over time. For example, Sichuan and Chongqing entered the fourth quadrant in 2017.

A few provinces show L-H and H-L clusters, and show negative spatial autocorrelation.Under the W1 matrix,there are 6 provinces (20\%), 8 provinces $(26.66 \%)$, and 11 provinces $(36.66 \%)$ located in the second and 
fourth quadrant in 2003,2010, and 2017.Under the W2 matrix,there are 7 provinces (23.33\%), 9 provinces (30\%), and 10 provinces $(33.33 \%$ ) located in the second and fourthquadrants in 2003,2010, and 2017.

Specifically, under the two spatial weight matrices, the provinces that are located in the second quadrant and present the L-H agglomeration mode are mainly distributed in the central and northeast regions, and have been stable at about 6 provinces . Anhui and Jilin are the most stable, and and they are all in the second quadrant from 2003 to 2017.Other provinces have entered other quadrants over time. For example, Henan entered and stabilized in the third quadrant in 2010.Located in the fourth quadrant, the provinces showing the H-L agglomeration pattern are scattered in various regions of the china. Over time, the fourth quadrant provinces have increased.However, no provinces remained stable in this quadrant from 2003 to 2017. Only Heilongjiang and Guangdong remained stable in this quadrant for most of the time. Other provinceshave changed significantly.

It can be seen that although the provinces in the first and third quadrants showing similar spatial correlation have decreased, the proportion still remains above $60 \%$. While the provinces in the second and fourth quadrants showing dissimilar spatial association have increased, the proportion is still less than $40 \%$. The provinces in the first and third quadrants are mostly concentrated in the eastern and western regions, while the provinces in the second and fourth quadrants are mostly concentrated in the central and northeastern regions. These all show that the TFEE of Chian has both spatial dependence and differences characteristics.

\subsection{Spatial econometric regression results}

According to the above analysis, We can known the TFEE exists significant spatial correlation and dependence.However, using ordinary regression models can underestimate or overestimate some influencing factors.Therefore, We chooses the spatial econometric model that can consider the spatial effect to test the driving factors of TFEE .Because, the spatial econometric model needs to be chosen by LM、LR and Wald test.Therefore We uses MATLAB software to carry out LM ,LR and Wald test.The results are shown in Table 6.

Table 6.OLS estimation and LM test results of China panel data from 2003 to 2017

\begin{tabular}{|c|c|c|c|c|c|c|c|}
\hline Variable & Coefficient & $\mathrm{T}$ & $\mathrm{P}$ & Variable & Coefficient & $\mathrm{T}$ & $\mathrm{P}$ \\
\hline Intercept & $1.8267^{* * * *}$ & 3.8355 & 0.0001 & InEI & $0.0662^{\text {***k }}$ & 2.5922 & 0.0099 \\
\hline InGDP & $-0.0989^{* * * *}$ & -2.9453 & 0.0034 & InRL & -0.1134 & -0.6630 & 0.5077 \\
\hline InTP & -0.0072 & -0.7471 & 0.4554 & InFDI & $0.0863^{* * * *}$ & 10.8968 & 0.0000 \\
\hline InIS & -0.0679 & -0.6230 & 0.5336 & InGZ & 1.5898 & 0.7361 & 0.4621 \\
\hline InJJ & -0.1244 & -1.3543 & 0.1763 & InGZ2 & -0.7995 & -0.7400 & 0.4597 \\
\hline InCITY & $0.4660^{* * * *}$ & 6.3965 & 0.0000 & & & & \\
\hline \multicolumn{8}{|c|}{ W-1 } \\
\hline \multicolumn{2}{|c|}{ LM-lag } & $49.6927^{* * * *}$ & 0.0000 & \multicolumn{2}{|c|}{ LM-error } & $21.9432^{* * *}$ & 0.0000 \\
\hline \multicolumn{2}{|c|}{ Robust LM-lag } & $34.1867^{* * *}$ & 0.0000 & \multicolumn{2}{|c|}{ Robust LM-error } & $6.4372^{* * *}$ & 0.0110 \\
\hline \multicolumn{2}{|c|}{ LR-lag } & $319.1642^{* * * *}$ & 0.0000 & \multicolumn{2}{|c|}{ LR-error } & $203.6862^{* * * *}$ & 0.0000 \\
\hline \multicolumn{2}{|c|}{ Wald-lag } & $454.2382^{* * * *}$ & 0.0000 & \multicolumn{2}{|c|}{ Wald-error } & $186.8330^{* * * *}$ & 0.0000 \\
\hline \multicolumn{8}{|c|}{ W-2 } \\
\hline \multicolumn{2}{|c|}{ LM-lag } & $64.5203^{* * *}$ & 0.0000 & \multicolumn{2}{|c|}{ LM-error } & $34.2378^{* * *}$ & 0.0000 \\
\hline \multicolumn{2}{|c|}{ Robust LM-lag } & $34.4697^{* * * *}$ & 0.0000 & \multicolumn{2}{|c|}{ Robust LM-error } & $4.1873^{* * * *}$ & 0.0110 \\
\hline \multicolumn{2}{|c|}{ LR-lag } & $289.9909^{* * * *}$ & 0.0000 & \multicolumn{2}{|c|}{ LR-error } & $162.9848^{* * * *}$ & 0.0000 \\
\hline \multicolumn{2}{|c|}{ Wald-lag } & $413.7529^{* * * *}$ & 0.0000 & \multicolumn{2}{|c|}{ Wald-error } & $142.1365^{* * * *}$ & 0.0000 \\
\hline
\end{tabular}
significance level test, indicating that the model has both spatial error and lag characteristics. Further analysis shows that both the LR test and Wald test pass the significance level test and refuse to reduce the spatial Durbin model (SDM) to the spatial lag model (SLM) or the spatial error model (SEM), so the spatial Dubin model should 
be the best select. Besides, based on the spatial durbin model, it is also necessary to compare and analyze the spatial durbin model of five type effect according to Anselin criterion, in order to select the best model.The test results are shown in Table 6 and Table 7. It can be seen that under the two spatial weight matrices, the $\mathrm{R}^{2}$ of the spatial Durbin model of the time and spatial double fixed effect are 0.9400 and 0.9409 , respectively, and the Log-L value are 752.4071 and 753.7171 , which are higher than the other four effects. Therefore, this article chooses the spatial Durbin model with time and spatial double fixed effect to test the driving factors of TFEE.

It can be seen from Table 7 and Table 8 , under the two spatial weight matrices, the lag coefficients $\mathrm{W}^{*}$ dep.var of the spatial Durbin model with time and spatial double fixed effec are 0.1865 and 0.3122 , which pass the $1 \%$ significance level test and show significant positive.This echoes the previous spatial autocorrelation results, and once again confirms that China's provincial TFEE has a significant and strong spatial correlation.It means that the TFEE of a provinces will be affected by the TFEE of neighboring provinces exceeding $18 \%$.Among them, under

446 the W2 matrix, the comprehensive effect of this spatial spillover is the strongest, reaching $31.2 \%$, while the effect of the W1 matrix reaches $18.6 \%$, which shows that the TFEE of China is being implemented. In econometric regression analysis, spatial effect is a factor that cannot be ignored.

Table 7. Estimation and test of SDM model(W-1)

\begin{tabular}{|c|c|c|c|c|c|}
\hline & & & & -1 & \\
\hline & No space effect & Spatial fixed effect & Time fixed effect & Time and space double fixed effect & Random effect \\
\hline \multirow{2}{*}{ InGDP } & $0.1608^{* * *}$ & -0.0035 & $0.1386^{* * *}$ & 0.0471 & $0.0734^{*}$ \\
\hline & $(6.0314)$ & $(-0.0726)$ & $(5.4216)$ & $(0.9346)$ & $(1.6698)$ \\
\hline \multirow{2}{*}{ InTP } & 0.0040 & 0.0181 & 0.0054 & $0.0307^{* * *}$ & 0.0137 \\
\hline & $(0.5520)$ & $(1.5892)$ & $(0.7712)$ & $(2.6806)$ & $(1.3425)$ \\
\hline \multirow{2}{*}{ InIS } & $-0.5010^{* * *}$ & $-0.2463^{* * *}$ & $-0.6315^{* * *}$ & $-0.3566^{* * *}$ & $-0.2981^{* * * *}$ \\
\hline & $(-6.1596)$ & $(-3.8591)$ & $(-7.6487)$ & $(-4.9257)$ & $(-4.7663)$ \\
\hline \multirow{2}{*}{ InJJ } & $0.2635^{* * *}$ & $0.3589^{* * * *}$ & $0.3750^{* * *}$ & $0.4127^{* * *}$ & $0.3504^{* * *}$ \\
\hline & $(3.8982)$ & $(6.7420)$ & $(5.4405)$ & $(7.4777)$ & $(6.6625)$ \\
\hline \multirow{2}{*}{ InCITY } & -0.0125 & $-0.3205^{* * *}$ & 0.0121 & $-0.3669^{* * *}$ & $-0.2617^{* * *}$ \\
\hline & $(-0.2288)$ & $(-5.6229)$ & $(0.2277)$ & $(-6.4124)$ & $(-4.7131)$ \\
\hline \multirow{2}{*}{ InEI } & -0.0323 & $-0.0708^{*}$ & $-0.0497^{* *}$ & $-0.0904^{* *}$ & $-0.0813^{* *}$ \\
\hline & $(-1.5296)$ & $(-1.9642)$ & $(-2.2896)$ & $(-2.4579)$ & $(-2.3781)$ \\
\hline \multirow{2}{*}{ InHI } & $0.2981^{\text {*** }}$ & 0.0389 & $0.2267^{*}$ & $0.3114^{* *}$ & 0.1738 \\
\hline & $(2.2412)$ & $(0.2683)$ & $(1.7476)$ & $(2.0054)$ & $(1.2392)$ \\
\hline \multirow{2}{*}{ InFDI } & $0.0252^{* * *}$ & 0.0087 & $0.0138^{* *}$ & -0.0007 & $0.0105^{*}$ \\
\hline & $(4.0502)$ & (1.5879) & $(2.2496)$ & $(-0.1136)$ & (1.9572) \\
\hline \multirow{2}{*}{ InGZ } & -0.2510 & $-2.3075^{\text {*** }}$ & -1.0310 & $-2.6432^{* * * k}$ & $-1.8997^{* *}$ \\
\hline & $(-0.1783)$ & $(-2.6368)$ & $(-0.7503)$ & $(-3.0124)$ & $(-2.1650)$ \\
\hline \multirow{2}{*}{ InGZ2 } & 0.1273 & $1.1461^{* * *}$ & 0.5190 & $1.3145^{\text {*** }}$ & $0.9421^{* *}$ \\
\hline & $(0.1808)$ & (2.6177) & $(0.7551)$ & $(2.9946)$ & $(2.1461)$ \\
\hline \multirow{2}{*}{$\mathrm{W} * \mathrm{InGDP}$} & $-0.2387^{* * *}$ & $-0.2800^{* * *}$ & $-0.1425^{* *}$ & $-0.1393^{*}$ & $-0.3361^{* * *}$ \\
\hline & $(-4.5281)$ & $(-4.8707)$ & $(-2.4851)$ & $(-1.6907)$ & $(-6.1314)$ \\
\hline \multirow{2}{*}{$\mathrm{W}^{*} \operatorname{InTP}$} & -0.0160 & 0.0184 & -0.0109 & $0.0589^{* * *}$ & 0.0159 \\
\hline & $(-1.4812)$ & (1.0639) & $(-0.9842)$ & $(2.8015)$ & (1.0203 ) \\
\hline \multirow[t]{2}{*}{$\mathrm{W}^{*} \mathrm{InIS}$} & $0.8345^{* * *}$ & 0.1304 & 0.0855 & -0.1501 & $0.2260^{* *}$ \\
\hline & $(6.5504)$ & $(1.3870)$ & $(0.4650)$ & $(-0.9365)$ & $(2.4379)$ \\
\hline \multirow{2}{*}{$\mathrm{W}^{*} \mathrm{InJJ}$} & $-0.9854^{* * *}$ & -0.1304 & $-0.3037^{*}$ & -0.0075 & $-0.2139^{* *}$ \\
\hline & $(-8.2309)$ & $(-1.3059)$ & $(-1.8449)$ & $(-0.0592)$ & $(-2.1799)$ \\
\hline
\end{tabular}




\begin{tabular}{lccccc}
\hline W*InCITY & $0.4654^{* * *}$ & $0.7600^{* * *}$ & $0.5064^{* * *}$ & $0.7233^{* * *}$ & $0.7395^{* * *}$ \\
& $(4.6206)$ & $(7.4341)$ & $(4.8972)$ & $(6.3171)$ & $(7.4040)$ \\
W*InEI & 0.1009 & $0.1228^{* *}$ & -0.0290 & -0.0535 & $0.1589^{* * *}$ \\
& $(2.7173)$ & $(2.1275)$ & $(-0.6818)$ & $(-0.6673)$ & $(2.9424)$ \\
W*InHI & $-0.4685^{* *}$ & -0.0231 & -0.1726 & $1.0226^{* * *}$ & -0.0121 \\
& $(-2.0423)$ & $(-0.0898)$ & $(-0.6528)$ & $(2.9662)$ & $(-0.0495)$ \\
W*InFDI & $0.0662^{* * *}$ & 0.0050 & 0.0092 & -0.0135 & 0.0104 \\
& $(5.8586)$ & $(0.4339)$ & $(0.6788)$ & $(-1.0486)$ & $(0.9353)$ \\
W*InGZ & $10.3450^{* *}$ & 3.2867 & 5.9594 & 3.5431 & 4.3405 \\
& $(2.2315)$ & $(1.1407)$ & $(1.2850)$ & $(1.2157)$ & $(1.5032)$ \\
W*InGZ2 & $-5.1702^{* *}$ & -1.6280 & -2.9756 & -1.7533 & -2.1542 \\
& $(-2.2296)$ & $(-1.1299)$ & $(-1.2826)$ & $(-1.2030)$ & $(-1.4918)$ \\
W*dep.var. & $0.3170^{* * *}$ & $0.2140^{* * *}$ & 0.0050 & $0.1865^{* * *}$ & $0.2580^{* * *}$ \\
& $(6.1077)$ & $(3.6802)$ & $(0.0783)$ & $(3.1794)$ & $(4.5742)$ \\
R-squared & 0.7995 & 0.9347 & 0.8252 & 0.9400 & 0.9290 \\
& & & & 752.4071 & -339422.02 \\
\hline
\end{tabular}

According to the regression results in Table 7 and Table 8, under the two spatial weight matrices, the 451 coefficients of technological progress(TP), industrial agglomeration(IG), and human capital(HI) passed the significance level test, and showed significantly positive.The coefficients of industrial structure(IS), energy 453 intensity(EI) and urbanization level(CITY) passed the significance level test and showed significantly 454 negative.The coefficients of environmental regulations(GZ) and its quadratic coefficients(GZ2) passed the 455 significance level test, and showed significantly positive and significant negative respectively,and showing a "U" 456 shape.The coefficient of economic development level (GDP) showed positive, but it fails the significance level 457 test.The coefficient of foreign direct investment(FDI) showed negative, but it fails the significance level test. All 458 driving factors will affect the TFEE through specific "polarization effect" and "trickle down effect", that is, the 459 TFEE of neighboring provinces will have a corresponding impact on the TFEE of the provinces . Each factor promotes the improvement of TFEE of the province, it will also be transmitted to neighboring provinces through 461 the spatial spillover mechanism, thereby promoting the common improvement of TFEE of neighboring provinces.

Table 8. Estimation and test of SDM model(W-2)

\begin{tabular}{|c|c|c|c|c|c|}
\hline & \multicolumn{5}{|c|}{$\mathrm{W}-2$} \\
\hline & No space effect & Spatial fixed effect & Time fixed effect & Time and space double fixed effect & Random effect \\
\hline \multirow{2}{*}{ InGDP } & $0.1246^{* * *}$ & -0.0267 & $0.1032^{* * *}$ & 0.0404 & $0.0701^{*}$ \\
\hline & $(4.8482)$ & $(-0.5704)$ & $(4.3127)$ & $(0.8483)$ & $(1.6612)$ \\
\hline \multirow{2}{*}{ InTP } & -0.0005 & $0.0202^{*}$ & 0.0031 & $0.0239^{* *}$ & 0.0171 \\
\hline & $(-0.0760)$ & $(1.7459)$ & $(0.4727)$ & $(2.1398)$ & $(1.6220)$ \\
\hline \multirow{2}{*}{ InIS } & $-0.5805^{* * *}$ & $-0.2507^{* * *}$ & $-0.7514^{* * *}$ & $-0.4315^{* * *}$ & $-0.3214^{* * *}$ \\
\hline & $(-6.7156)$ & $(-3.7952)$ & $(-9.1374)$ & $(-5.9685)$ & $(-4.9558)$ \\
\hline \multirow{2}{*}{ InJJ } & $0.3021^{* * *}$ & $0.3707^{* * * *}$ & $0.4533^{* * *}$ & $0.4356^{* * *}$ & $0.3649^{* * *}$ \\
\hline & $(4.2271)$ & $(6.8464)$ & $(6.6698)$ & $(8.0494)$ & $(6.7669)$ \\
\hline \multirow{2}{*}{ InCITY } & $0.0974^{*}$ & $-0.3948^{* * *}$ & $0.1071^{* *}$ & $-0.3822^{* * * *}$ & $-0.3155^{* * *}$ \\
\hline & (1.7999 & $(-6.5982)$ & $(2.1661)$ & $(-6.4089)$ & $(-5.4532)$ \\
\hline \multirow{2}{*}{ InEI } & $-0.0785^{* * *}$ & $-0.0807^{* * * *}$ & $-0.0823^{* * *}$ & $-0.0632^{* *}$ & $-0.0933^{* * * *}$ \\
\hline & $(-3.7787)$ & $(-2.6403)$ & $(-4.1628)$ & $(-2.0312)$ & $(-3.1859)$ \\
\hline
\end{tabular}




\begin{tabular}{|c|c|c|c|c|c|}
\hline \multirow{2}{*}{ InHI } & 0.0546 & 0.1277 & 0.0606 & $0.2590^{*}$ & $0.2707^{*}$ \\
\hline & $(0.4148)$ & $(0.8680)$ & $(0.4854)$ & $(1.6624)$ & $(1.8987)$ \\
\hline \multirow{2}{*}{ InFDI } & $0.0331^{* * *}$ & $0.0095^{*}$ & $0.0267^{* * *}$ & 0.0040 & $0.0092^{*}$ \\
\hline & $(4.8362)$ & (1.7015 ) & (4.1817) & $(0.7178)$ & (1.6516) \\
\hline \multirow{2}{*}{ InGZ } & -0.0101 & $-2.8298^{* * *}$ & -0.9138 & $-2.8683^{* * *}$ & $-2.1895^{* *}$ \\
\hline & $(-0.0071)$ & $(-3.2018)$ & $(-0.6810)$ & $(-3.2923)$ & $(-2.4727)$ \\
\hline \multirow{2}{*}{ InGZ2 } & 0.0044 & $1.4054^{* * *}$ & 0.4562 & $1.4267^{* * *}$ & $1.0858^{* *}$ \\
\hline & $(0.0061)$ & (3.1793) & $(0.6796)$ & (3.2738) & $(2.4515)$ \\
\hline \multirow{2}{*}{$\mathrm{W}^{*} \mathrm{InGDP}$} & $-0.3828^{* * *}$ & $-0.2388^{* * *}$ & -0.0947 & $0.3374^{* * *}$ & $-0.3149^{* * *}$ \\
\hline & $(-6.1462)$ & $(-3.4712)$ & $(-1.3186)$ & $(2.6235)$ & $(-4.8991)$ \\
\hline \multirow{2}{*}{$\mathrm{W} * \operatorname{InTP}$} & 0.0130 & $0.0369^{*}$ & 0.0177 & $0.1135^{* * *}$ & 0.0331 \\
\hline & $(0.8482)$ & (1.6666 ) & $(1.0410)$ & $(4.0870)$ & $(1.6237)$ \\
\hline \multirow{2}{*}{$\mathrm{W}^{*} \mathrm{InIS}$} & $0.7194^{* * *}$ & 0.0333 & $-0.3645^{*}$ & $-0.7519^{* * *}$ & 0.1660 \\
\hline & (5.2404) & $(0.3122)$ & $(-1.8206)$ & $(-4.0617)$ & $(1.5958)$ \\
\hline \multirow{2}{*}{$\mathrm{W} * \mathrm{InJJ}$} & $-0.7757^{* * *}$ & -0.0794 & 0.0996 & 0.2319 & $-0.2099^{*}$ \\
\hline & $(-6.1145)$ & $(-0.6540)$ & $(0.5939)$ & (1.5909) & $(-1.7974)$ \\
\hline \multirow{2}{*}{$\mathrm{W}^{*} \mathrm{InCITY}$} & $0.8277^{* * *}$ & $0.7626^{* * *}$ & $0.5772^{* * *}$ & $0.7203^{* * *}$ & $0.7252^{* * *}$ \\
\hline & $(6.1718)$ & (6.1351) & $(4.2150)$ & $(5.1861)$ & $(5.9626)$ \\
\hline \multirow{2}{*}{$\mathrm{W} * \mathrm{InEI}$} & $0.2042^{* * *}$ & $0.1744^{* *}$ & 0.0130 & 0.0530 & $0.2219^{* * *}$ \\
\hline & (3.8771) & $(2.4514)$ & $(0.2019)$ & $(0.5067)$ & $(3.3445)$ \\
\hline \multirow{2}{*}{$\mathrm{W} * \mathrm{InHI}$} & -0.1641 & -0.2026 & -0.1432 & 0.6764 & -0.0979 \\
\hline & $(-0.5635)$ & $(-0.5787)$ & $(-0.3867)$ & $(1.3811)$ & $(-0.3064)$ \\
\hline \multirow{2}{*}{$\mathrm{W}^{*} \mathrm{InFDI}$} & $0.0393^{* *}$ & 0.0034 & $-0.0533^{* * *}$ & -0.0015 & 0.0108 \\
\hline & $(2.4768)$ & $(0.2304)$ & $(-2.7897)$ & $(-0.0956-$ & $(0.7522)$ \\
\hline \multirow{2}{*}{$\mathrm{W}^{*} \mathrm{InGZ}$} & 3.8123 & 3.6953 & -0.8615 & 3.6441 & $4.1546^{*}$ \\
\hline & $(0.9923)$ & $(1.5602)$ & $(-0.2222)$ & $(1.4570)$ & (1.7467 ) \\
\hline \multirow{2}{*}{$\mathrm{W}^{*} \mathrm{InGZ2}$} & -1.9013 & -1.8298 & 0.4458 & -1.7970 & $-2.0591^{*}$ \\
\hline & $(-0.9894)$ & $(-1.5451)$ & $(0.2298)$ & $(-1.4368)$ & $(-1.7312)$ \\
\hline \multirow{2}{*}{$\mathrm{W}^{*}$ dep.var. } & $0.1660^{* *}$ & $0.3580^{* * *}$ & $-0.3280^{* * *}$ & $0.3122^{* * *}$ & $0.4030^{* * *}$ \\
\hline & (2.3779) & $(5.3957)$ & $(-4.0635)$ & $(4.6562)$ & $(6.3681)$ \\
\hline R-squared & 0.7894 & 0.9336 & 0.8317 & 0.9409 & 0.9274 \\
\hline log-likelihood & 470.3054 & 725.3694 & 517.1195 & 753.71711 & -200751.93 \\
\hline
\end{tabular}

However, according to the related theory of LeSage and Pace ( LeSage and Pace 2009), when the spatial

464 lagging explanatory variable and the explained variable are included in the spatial econometric model the 465 estimated coefficient cannot directly reflect the marginal effect like the traditional econometric model. Obtain the average spillover effect on adjacent regions when the regional explanatory variables change, and decompose it into

467 direct effects (effects on this region), indirect effects (spillover effects on neighboring regions) and total effects 468 (comprehensive effect), and then proceed statistical testing (Elhorst 2010; Elhorst and Fréret 2010). It can be seen 469 that a more scientific and reasonable way is to analyze by observing direct effects and indirect effects. Therefore, 470 this article uses direct effects and indirect effects to observe the impact of each driving factorson the TFEE. The 471 results are shown in Table 9.

(1)The regression results show that under the W1 matrix and W2 matrix, the direct effect coefficients of the economic development level are 0.0411 and 0.0602 . Although the coefficient direction is positive, none of them 474 passed the significance test.This shows that economic development on the improvement of TFEE is not obvious. The traditional extensive development model consumes a lot of fossil energy and produces more pollution 
emissions, which makes the environmental cost of economic development continue to rise. However, as the economy continues to develop, new energy sources,energy-saving and consumption-reducing technologies continue to emerge, and the negative environmental externalities at the initial stage of development are gradually offset.At this stage, the development model of china is gradually shifting from extensive model to high-quality model. In the process of transformation, although the negative environmental externalities are gradually offset, the policy, technology, management and other aspects are still not perfect.As a result, the TFEE cannot be improved well.The indirect effect coefficients of the economic development level are -0.1551 and 0.4931 . The coefficients under the W1 matrix have not passed the significance test, and the coefficients under the W2 matrix have passed the 5\% significance test.It shows that the level of economic development will produce significant positive spatial spillover effects within a certain distance.This may be because the economic development of various provinces in China has a better linkage mechanism. The economic development of this province can produce positive externalities and demonstration effects, which can promote the transfer of new energy and energy-saving emission reduction technologies that it has mastered to neighboring provinces,thereby promoting the improvement of TFEE of neighboring provinces.

(2)Under the W1 matrix and W2 matrix, the direct effect coefficients of technological progress are 0.0341 and 0.0306, and the indirect effect coefficients are 0.0764 and 0.1720 . They all have passed the $1 \%$ significance test and are significantly positive. This shows that technological progress can not only significantly improve the TFEE of this province, but also can significantly promote the TFEE of neighboring provinces.Technological progress can effectively promote the innovation of production technology, promote the popularization of advanced technologies such as energy-saving,new energy,low-carbon, and pollution control, and help improve the utilization efficiency of resources and energy in the production process, and reduce the production and discharge of pollutants. Therefore, technological progress is not only conducive to improving the TFEE of the province, but also has a positive effect on the improvement of the TFEE of neighboring provinces .

(3)Under the W1 matrix and W2 matrix, the direct effect coefficients of the industrial structure are -0.3635 and -0.4874 , and both pass the $1 \%$ significance test,showing that the industrial structure has an inhibitory effect on the improvement of TFEE.The higher the proportion of the secondary industry, the higher the consumption of fossil energy. As the main producer of environmental pollution, fossil energy will generate numerous three waste emissions(solid waste, $\mathrm{CO} 2, \mathrm{SO}$, and wastewater) during economic operation, which will worsen the ecological environment. China's economic development is in a critical transition period,but the secondary industry, which is characterized by "three high"(high investment, high energy consumption, and high pollution), still occupies the dominant position, and its negative impact on TFEE will continue to exist.The indirect effect coefficients of the industrial structure are -0.2526 and -1.2407 . The coefficients under the W1 matrix have not passed the significance test, and the coefficients under the W2 matrix have passed the $1 \%$ significance test, showing that the industrial structure has an obvious negative spillover effect, that is, the industrial structure of the province can restrain the improvement of the TFEE of neighboring provinces, and the strength of the spillover effect will vary with distance.

The reason is that the industrial structure, as a significant bond between economic activities and the ecological environment,plays a crucial part in resource allocation, resource consumption, and the types and quantities of pollutants discharged through structural adjustments that affect changes in input and output elements. The 
measures will inhibit the improvement of TFEE in neighboring provinces.

(4)Under the W1 matrix and W2 matrix, the direct effect coefficients of industrial agglomeration are 0.4135 and 0.4607 , and both pass the $1 \%$ significance test, showing that the industrial agglomeration promotes the improvement of TFEE.Industrial agglomeration is an inevitable choice for the development of industrialization. In the initial stage of industrial agglomeration, the agglomeration effect brought about product exchange symbiosis, infrastructure and technology spillover sharing, which is conducive to the positive externality of the agglomeration. but with the continuous expansion of industrial agglomeration, the congestion effect caused by resource shortage and environmental pollution will gradually offset the positive externalities of agglomeration. At this stage, the level of industrialization in china is still low, and industrial agglomeration is still in the growth stage.Industrial agglomeration will still promote the improvement of TFEE.The indirect effect coefficients of industrial agglomeration are 0.0767 and 0.5196.The coefficients under the W1 matrix have not passed the significance test, and the coefficients under the W2 matrix have passed the 5\% significance test.It shows that industrial agglomeration has an obvious positive spillover effect, that is, industrial agglomeration in province can promote the improvement of TFEE in adjacent provinces, and the strength of the spillover effect will vary with distance.The reason may be that the positive effects of industrial agglomeration will lead to industrial transfer in neighboring provinces. The relocation of "high pollution, high consumption and high input" industries provides favorable conditions for the improvement of TFEE in neighboring provinces. Besides, the industrial agglomeration in the province drives the development of nearby enterprises to cluster. The positive effect of industrial agglomeration promotes the improvement of TFEE in the neighboring province, but this positive effect will gradually be offset over time.

(5)Under the W1 matrix and W2 matrix, the direct effect coefficients of the urbanization level are -0.3383 and -0.3463 respectively, and both passed the $1 \%$ significance test, indicating that the urbanization level has an inhibitory effect on the improvement of TFEE.China's urbanization is in an accelerated stage, and urban problems begin to emerge.First, it has increased the pressure on land resources, water resources, and energy. Second, a large number of agricultural populations have entered cities, increasing pollution, resulting in the continuous deterioration of urban ecological environment quality.Thus inhibiting the improvement of TFEE.The indirect effect coefficients of the urbanization level are 0.7739 and 0.8347 ,both of which pass the $1 \%$ significance level test and are significantly positive.It shows that urbanization level has an obvious positive spillover effect, that is, urbanization level in province can promote the improvement of TFEE in neighboring provinces. This may be because the higher the level of urbanization, the more infrastructure construction and the inflow of rural population will increase. These will aggravate the population, resources and environmental pressures of the provinces, but can greatly alleviate the population, resources and environmental pressure. Simultaneously, when the urbanization process in a province is relatively smooth, it will indirectly stimulate the speed of urbanization in neighboring provinces , thereby promoting the improvement of TFEE in neighboring provinces.

(6)Under the W1 matrix and W2 matrix, the direct effect coefficients of energy intensity are -0.0935 and -0.0623 , and pass the 5\% and 10\% significance tests, respectively, indicating that energy intensity has an inhibitory effect on improving TFEE.The higher the energy intensity, the greater the pressure it brings to the environment, resulting in increasing pressure on China's ecological environment year by year, and triggering a series of 

consumption structure of China's provinces is dominated by highly polluting coal, and the energy structure is unreasonable, which makes energy consumption pay a large ecological cost while promoting economic development, which greatly restricts the improvement of TFEE. The indirect effect coefficients of energy intensity are -0.0841 and 0.0443 respectively, and none of them pass the significance test, indicating that energy intensity cannot produce significant spatial spillover effects.

(7)Under the W1 matrix and W2 matrix, the direct effect coefficients of human capital are 0.3718 and 0.3044 , and passed the 5\% and 10\% significance tests respectively, indicating that human capital can promote the improvement of TFEE.Higher human capital not only contributes to technological innovation, promotes technological progress, but also improves management level and promotes institutional innovation,thereby improving the efficiency of natural resources utilization and achieving the purpose of promoting the improvement of TFEE.In recent years, with the high speed development of China,the education level of residents has also risen sharply, and human capital has made great progress, which has greatly promoted the improvement of TFEE.The indirect effect coefficients of human capital are 1.3165 and 1.0507.The coefficients under the W1 matrix passed the $1 \%$ significance test, and the coefficients under the W2 matrix no passed the significance test, showing that human capital has an obvious positive spillover effect, That is, the human capital of the province can promote the improvement of the TFEE of neighboring provinces,and the strength of the spillover effect will vary with distance.The promotion of human capital is conducive to the formation of talent aggregation phenomenon, which makes the provinces present the trend of increasing talents, technology and other elements. When the elements gather to a certain scale, it will produce spillover effects of technology and knowledge, spread to neighboring provinces, and promote the improvement of TFEE in neighboring provinces.

(8)Under the W1 matrix and W2 matrix, the direct effect coefficients of foreign direct investment are -0.0013 , 0.00369 , and the indirect effect coefficients are $-0.0157,-0.0018$, None of them passed the significance test,This shows that the foreign direct investment cannot play an effective role in the TFEE of this province and neighboring provinces.China is at the bottom of the industrial chain in the process of introducing foreign capital.Most of the FDI enterprises are mainly pollution-intensive enterprises.Through the linkage effects of upstream and downstream industries, polluting industries have shifted from developed countries to China, which has aggravated China's natural resources consumption and the deterioration of the ecological environment, making China became the developed countries of the "pollution haven".However, the advanced production technology, technical equipment and management experience mastered by FDI companies have also overflowed to a certain

582 extent,thereby offsetting some of the negative effects caused by FDI.This results in a situation where although there will be a negative effect, the effect is not significant.

(9)Under the W1 matrix and W2 matrix, the direct effect coefficients of the primary term of environmental regulation are -2.4732 and -2.7287 , respectively, and passing the $5 \%$ and $1 \%$ significance tests, and are significantly negative. While the direct effect coefficients of the secondary term of environmental regulation are are -1.2303 and 1.3584 , respectively, and passing the $5 \%$ and $1 \%$ significance level tests respectively, and are significantly positive.This shows that there is a U-shaped relationship between environmental regulation and TFEE.

589 Before the U-shaped turning point, China's environmental pollution control investment level was low, and its effect 
on the improvement of the ecological environment was very limited. Besides, due to the increase in government investment in governance, it would squeeze out economic construction expenditures, which was not conducive to economic growth, therefore, the strengthening of environmental regulation will lead to the decline of TFEE.After the U-shaped turning point, the government's investment in the three waste treatment projects is at a relatively high level. The equipment and technology used for environmental pollution treatment have been greatly improved due to financial support. The effect of environmental pollution control began to appear, and environmental regulation began to promote the improvement of TFEEThe effect coefficients of the primary term of environmental regulation are 3.8614 and 3.7301 , respectively, and the indirect effect coefficients of the secondary term of environmental regulation are -1.9017 and -1.8338 , respectively. All of them no passed the significance test, indicating that the spatial spillover effect of environmental regulation is not significant and cannot have a significant impact on the TFEE in neighboring provinces.

Table 9.Effect decomposition of SDM model with spatial-temporal double fixed effect

\begin{tabular}{|c|c|c|c|c|c|c|}
\hline & & $\mathrm{W}_{1}$ & & & $\mathrm{~W}_{2}$ & \\
\hline & Direct & Indirect & Total & Direct & Indirect & Total \\
\hline \multirow{2}{*}{ InGDP } & 0.0411 & -0.1551 & -0.1140 & 0.0602 & $0.4931^{* *}$ & $0.5533^{\text {** }}$ \\
\hline & $(0.8284)$ & $(-1.5683)$ & $(-0.9821)$ & (1.1997) & $(2.6751)$ & $(2.6848)$ \\
\hline \multirow{2}{*}{ InTP } & $0.0341^{* * * *}$ & $0.0764^{* * * *}$ & $0.1105^{* * *}$ & $0.0306^{* * * *}$ & $0.1720^{* * * *}$ & $0.2026^{* * *}$ \\
\hline & (3.0138) & (3.1479) & (4.1573) & $(2.8926)$ & $(4.5282)$ & (5.1975) \\
\hline \multirow{2}{*}{ InIS } & $-0.3635^{* * *}$ & -0.2526 & $-0.6161^{* *}$ & $-0.4874^{* * *}$ & $-1.2407^{* * * *}$ & $-1.7281^{* * *}$ \\
\hline & $(-4.7936)$ & $(-1.2593)$ & $(-2.5712)$ & $(-6.2644)$ & $(-4.4816)$ & $(-5.4774)$ \\
\hline \multirow{2}{*}{ InJJ } & $0.4135^{* * *}$ & 0.0767 & $0.4903^{* *}$ & $0.4607^{* * * *}$ & $0.5196^{* *}$ & $0.9803^{* * *}$ \\
\hline & (7.1362) & $(0.4931)$ & (2.7099) & (8.0799) & $(2.5436)$ & (4.3135) \\
\hline \multirow{2}{*}{ InCITY } & $-0.3383^{* * *}$ & $0.7739^{* * * *}$ & $0.4355^{* * *}$ & $-0.3463^{* * *}$ & $0.8347^{* * * *}$ & $0.4884^{* *}$ \\
\hline & $(-6.2239)$ & (5.7464) & (3.0364) & $(-6.0338)$ & $(4.2308)$ & (2.3453) \\
\hline \multirow{2}{*}{ InEI } & $-0.0935^{* *}$ & -0.0841 & -0.1776 & $-0.0623^{*}$ & 0.0443 & -0.0180 \\
\hline & $(-2.5101)$ & $(-0.9062)$ & $(-1.6640)$ & $(-1.8527)$ & $(0.2949)$ & $(-0.1095)$ \\
\hline \multirow{2}{*}{ InHI } & $0.3718^{* *}$ & $1.3165^{* * *}$ & $1.6883^{* * *}$ & $0.3044^{*}$ & 1.0507 & $1.3551^{*}$ \\
\hline & $(2.4178)$ & (3.1312) & (3.3694 ) & (1.8446) & (1.4907) & (1.7099) \\
\hline \multirow{2}{*}{ InFDI } & -0.0013 & -0.0157 & -0.0170 & 0.0039 & -0.0018 & 0.0021 \\
\hline & $(-0.2163)$ & $(0.9637)$ & $(-0.8445)$ & $(0.7052)$ & $(-0.0796)$ & $(0.0869)$ \\
\hline \multirow{2}{*}{ InGZ } & $-2.4732^{* *}$ & 3.8614 & 1.3883 & $-2.7287^{* * *}$ & 3.7301 & 1.0014 \\
\hline & $(-2.7096)$ & (1.1017) & $(0.3573)$ & $(-3.0705)$ & (1.0096) & $(0.2446)$ \\
\hline \multirow{2}{*}{ InGZ2 } & $1.2303^{* *}$ & -1.9107 & -0.6804 & $1.3584^{* * *}$ & -1.8338 & -0.4754 \\
\hline & $(2.6944)$ & $(-1.0904)$ & $(-0.3503)$ & $(3.0562)$ & $(-0.9925)$ & $(-0.2322)$ \\
\hline
\end{tabular}

\section{Conclusions and policy implications}

In this article, a total factor ecological efficiency (TFEE) considering input, desirable output and undesirable output was constructed, based on the total factor analysis framework.Next,a hybrid distance Super-EBM model considering undesirable output was proposed to evaluate China's TFEE in three dimensions (national-regional-provincial) from2003 to 2017.Then, ESDA model was conducted to reveal the spatiotemporal characteristics and spatial effects of TFEE.Finally, the Spatial Durbin model(SDM) with spatial-temporal double fixed effectsis selected to test the driving factors and spatial spillover effects of China's TFEE. To sum up, the following main 
findings can be drawn.

First, from a national perspective,although China's TFEE is relatively high ,China's overall TFEE showed a downward trend during the 2003 to 2017; From a regional perspective,the TFEE of the four regions have not been achieve effective, and there are obvious differences between regions, showing an arrangement pattern of eastern region> northeastern region> central region> western region; From a provincial perspective,the TFEE of Beijing,Tianjin,Shanghai are efficient,and shows that the TFEE of these provinces is above the frontier, and reach the optimal configuration. The TFEE of other provinces has not been effective, and their input and outputare in an inefficient state, and the optimal configuration has not been achieved, and there is still room for improvement to varying degrees.Besides, the development trend of provinces with high TFEE is unstable enough,and the average annual growth rate is low, and they are mainly distributed in the northeast and eastern regions.The provinces with low TFEE have a relatively stable development trend and a high average annual growth rate, mainly distributed in the central and western regions.

Second, the TFEE of China has a positive spatial autocorrelation, and showing a strong spatial agglomeration.However, Moran's I index showed a fluctuating dynamic trend during 2003 to 2017, showing that the spatial distribution pattern of TFEE in China was unstable and easy to change.Further,Moran scatter plot indicates that the provinces of first and third quadrants are mostly distributed in the eastern and western regions, while the provinces of second and fourth quadrants are mostly concentrated in the central and northeastern regions.These all show that china's provincial TFEE has both spatial dependence characteristics and spatial differences characteristics.

Third, the spillover effect of TFEE in province would enhance the TFEE of neighboring provinces is supported by the Spatial Durbin model with spatial-temporal double fixed effectsis .The results show that most factors are related to TFEE to varying degrees, in which, TP,JJ and HC play a positive in TFEE , and IS,CITY, and EI play a negative role in TFEE. Furthermore,ER show U type of relationship with TFEE.GDP and FDI cannot have a significant impact on TFEE at this stage.Finally, the spatial spillover effects of TP, IS.JJ, CITY, and HC are proved to exist, showing that these independent variables in province impact the TFEE in neighboring provinces.

Based on the conclusion, this article puts forward a series of meaningful policy implications:

(1)China should accelerate the transformation of economic development mode and attach importance to resource consumption and environmental constraints in the process of economic development. Under the guideline of sustainable development and ecological civilization construction, china should follow the laws of nature, attach importance to environmental protection and enhance the efficiency of resource utilization. The government should abolish the "GDP-only theory", improve the "green" assessment system based on TFEE and improve the environmental protection awareness of governments at all levels in the process of development.

(2)Because ,the TFEE of China's regional, provincial exist significant differences ,so it is must to break the regional blockade and benefit barriers, break system disorder impeding the ability of a regional cooperation, to strengthen the regional cooperation, promote the free flow of capital, labor, technology, etc, to achieve the gradient transfer of high-quality talents, high technology and advanced management mode, and then reduce the regional difference of TFEE.Besides, China should actively promote the "top-down" overall economic development planning,avoid homogeneous competition among provinces, and speed up the formation of a new coordinated 
development mechanism for joint prevention and control of ecological environment.

(3)China's TFEE has significant positive spatial correlation and agglomeration characteristics. Therefore, for the central and western regions with low level TFEE agglomeration, while vigorously promoting technological and structural emission reduction, emphasis should be placed on the development of industries with high added value ,low carbon and environmental protection;At the same time, central and western regions should actively carry out extensive and specialized division of labor and cooperation with the eastern and northeastern regions, and accelerate the construction of industries closely related to the leading industries in the eastern and northeastern regions,so as to promote the optimization and upgrading of the industrial structure. Provinces with high TFEE in the eastern and northeast regions should provide corresponding technical assistance to the central and western regions, actively publicize and impart advanced experience in resource utilization and environmental protection, vigorously carry out technical exchanges and cooperation in the field of energy and environment.

(4)According to the test results of influence factors and spatial spillover effect of China's TFEE.First, china should adhere to the strategy of upgrading and development of industrial structure, resolutely close down and eliminate the"three high"(high investment, high energy consumption, and high pollution) enterprises, and take the market as the guide to let enterprises and industrial development survive. At the same time, china should actively guide the orderly transfer of industries to achieve scientific upgrading of industrial structure. Second, china should adhere to the strategy of driving technological innovation, constantly improve our capacity for independent innovation, and realize the transformation from economies of scale to economies of technology. Third, china should strengthen environmental regulations, introduce more stringent and effective policies for resource and environmental management, and regulate the structure and scale of energy, land and water resources utilization. At the same time, china will further refine all kinds of environmental protection rules and regulations, set specific, operable and quantifiable emission reduction targets for environmental protection, and severely punish illegal enterprises and excessive emissions, so as to reduce environmental pollution at source. Fourth, with the construction of high-level industrial agglomeration areas as the entry point for future development, efforts should be made to improve the integration degree of traditional leading industries and appropriately develop emerging industries, so as to continuously expand the regional industrial clusters to realize the interaction between industry and city and green development, and to optimize the resource allocation between regions through coordination.

\section{Declarations}

Ethical Approval: Not applicable

\section{Consent to Participate: Not applicable}

Consent to Publish:Not applicable

Availability of data and materials:The data used in this article can be found in the "China statistical yearbook", "China energy statistical yearbook" and "China environment yearbook".

Competing interests: The authors declare no conflict of interest.

Funding: The Key Program of National Social Science Foundation of China (No.17AJL008), The National Natural Science Foundation of China Program (No.62073198)

Author Contributions: Li Chengyu ,Zhang Yongmei and Zhang Shiqiang designed the whole study; Li Chengyu and Wang Jianmei conducted data collection, modeling, and results analysis; Li Chengyu wrote the paper.

Acknowledgments: This study is sponsored by the Key Program of National Social Science Foundation of China (No.17AJL008), the National Natural Science Foundation of China Program (No.62073198) 


\section{References}

Alizadeh S, Zafari-koloukhi H, Rostami F(2020) Rouhbakhsh,M.;Avami,A.Eco-efficiency of electric vehicles in the United States: A life cycle assessment based principal component analysis. J Clean Prod 249:119327

Andersen P, Petersen N(1993) A procedure for ranking efficient units in data envelopment analysis. Manag Sci 39 (10):1261-1264

Anselin L, Florax R, Rey S(2004) Advanced in spatial econometrics: methodology tools and applications. Berlin: Springer Science\&Business Media

Avkiran K, Tone K, Tsutsui M(2008) Bridging radial and non-radial measures of efficiency in DEA.Ann. Oper Res 164(1):127-138

Bai Y, Deng X, Jiang S, Zhang Q, Wang Z(2018) Exploring the relationship between urbanization and urban ecoefficiency: evidence from prefecture-level cities in China. J Clean Prod 195:1487-1496

Charnes A, Cooper W, Rhodes E(1978) Measuring the Efficiency of Decision Making Units.European Journal of Operational Research 2:429-444

Dong F, Zhang Y, Zhang X(2020) Applying a data envelopment analysis game cross-efficiency model to examining regional ecological efficiency: Evidence from China.J Clean Prod 267:122031

Elhorst J(2010) Applied Spatial Econometrics: Raising the Bar. Spatial Economic Analysis 5(01):9-28

Elhorst J, Fréret S(2010) Evidence of Political Yardstick Competition in France Using a Two-Regime Spatial Durbin Model with Fixed Effects. Social Science Electronic Publishing 49(05):931-951

Guan D,Liu Z, Geng Y(2012) The gigatonne gap in China's carbondioxide inventories.Nature Climate Change 2(9) $: 672-675$

LeSage J, Pace K(2009) Introduction to Spatial Econometrics. Boca Raton,USA,CRC Press

Li C, Zhang S,Zhang W (2018) Spatial Distribution Characteristics and Influencing Factors of China's Inter Provincial Industrial Eco-efficiency. Scientia Geographica Sinica 38(12):1970-1978

Li D, Zhu J, Hui C, Leungb B, Li Q(2011) An emergy analysis-based methodology for eco-efficiency evaluation of building manufacturing. Ecological Indicators 11(5):1419-1425

Li G, Fang C, Wang S, Sun S(2016) The effect of economic growth, urbanization, and industrialization on fine particulate matter (PM2.5) concentrations in China. Environ Sci Technol 50 (21):11452-11459

Litos L, Gray D, Johnston B, Morgan D, Evans S(2017) A maturity-based improvement method for eco-efficiency in manufacturing systems. Procedia Manuf 8:160-167

Liu J, Zhang J, Fu Z(2017) Tourism eco-efficiency of Chinese coastal cities - Analysis based on the DEA-Tobit model. Ocean \& Coastal Management 148:164-170

Liu Q, Wang S, Li B, Zhang W(2020) Dynamics, differences, influencing factors of eco-efficiency in China: A spatiotemporal perspective analysis.Journal of Environmental Management 264:110442

Liu Y, Zou L, Wang Y(2020) Spatial-temporal characteristics and influencing factors of agricultural eco-efficiency in China in recent 40 years.Land Use Policy 97:104794

Liu Z, Guan D, Wei W(2015) Reduced carbon emission estimates from fossil fuel combustion and cement production in China.Nature 524:7565, 335-338

Liu Z, Zhang H, Zhang Y, Zhu T(2020) How does industrial policy affect the eco-efficiency of industrial sector? Evidence from China.Applied Energy 272:115206

Long X, Zhao X, Cheng F(2015) The comparison analysis of total factor productivity and eco-efficiency in China's cement manufactures.Energy Policy 81:61-66

Mavi P,Saen R, Goh M(2019) Joint analysis of eco-efficiency and eco-innovation with common weights in twostage network DEA: A big data approach.Technological Forecasting and Social Change 144:553-562 
Merlinab M, Boileaua H(2017) Eco-efficiency and entropy generation evaluation based on emergy analysis:Application to two small biogas plants. J Clean Prod 143:257-268

Mickwitz P, Melanen M, Rosenstrom U, Seppala J(2016) Regional eco-efficiency indicators-a participatory approach. J Clean Prod 14 (18):1603-1611

Moutinho V, Madaleno M, Macedo P, Robaina M, Marques C(2018) Efficiency in the European agricultural sector: environment and resources. Environ Sci Pollut Res 25 (18):17927-17941

Moutinho V, Madaleno M, Macedo P(2020) The effect of urban air pollutants in Germany: eco-efficiency analysis through fractional regression models applied after DEA and SFA efficiency predictions. Sustainable Cities and Society 59:102204

Onat N, Kucukvar M, Afshar S(2019) Eco-efficiency of electric vehicles in the United States: A life cycle assessment based principal component analysis. J Clean Prod 212:515-526

Organization for Economic Cooperation and Development. Eco-efficiency(1998) Pairs: Organization for Economic Cooperation and Development.

Pace R, Lesage J(2009) A sampling approach to estimate the log determinant used in spatial likelihood problems. J Geogr Syst 11 (3):209-225

Ren Y, Fang C, Li G(2020) Spatiotemporal characteristics and influential factors of eco-efficiency in Chinese prefecture-level cities: A spatial panel econometric analysis.J Clean Prod 260:120787

Schaltegger S, Sturm A(1990) Okologische rationalitat: ansatzpunktezur ausgestaltung vonokologieorientierten management instrumenten. Unternehmung 44(4):273-290

Storto C(2016) Ecological Efficiency Based Ranking of Cities: A Combined DEA Cross-Efficiency and Shannon's Entropy Method.Sustainability 8(2):1-29

Storto C(2020) Measuring the efficiency of the urban integrated water service by parallel network DEA: The case of Italy. J Clean Prod 276:123170

Tone K(2001) Slacks-based Measure of Efficiency in Data Envelopment Analysis.European Journal of Operational Research 30:498-509

Tone K, Tsutsui M(2010) An epsilon-based measure of efficiency in DEA-a third pole of technical eficiency. Eur J Oper Res 207 (3):1554-1563

Tu Z, Hu T, Shen R (2019)Evaluating public participation impact on environmental protection and ecological efficiency in China: evidence from PITI disclosure. China Econ Rev 55:11-123

Wang Q, Wu S, Zeng Y, Wu B(2016) Exploring the relationship between urbanization, energy consumption, and CO2 emissions in different provinces of China Renew Sustain Energy Rev 54:1563-1579

Wang W, Jiang D, Chen D, Chen Z, Zhou W, Zhu B(2016) A Material Flow Analysis (MFA)-based potential analysis of eco-efficiency indicators of China'scement and cement-based materials industry. J Clean Prod 112:787796

Wang X, Ding H, Liu(2019) Eco-efficiency measurement of industrial sectors in China: A hybrid super-efficiency DEA analysis. J Clean Prod 229:53-64

Wang X, Wu Q, Majeed S, Sun D(2018) Fujian's industrial eco-efficiency:evaluation based on SBM and the empirical analysis of Influencing factors.Sustainability 10 (9):3333-3351

World Business Council for Sustainable Development(2000) Eco-efficient leadership for improved economic and environmental performance.Geneva: World Business Council for Sustainable Development

Wu Y, Ke Y, Xu C, Xiao X, Hu Y(2018) Eco-efficiency measurement of coal-fired power plants in China using super efficiency data envelopment analysis.Sustainable Cities \& Society 36:157-168

Yang L, Yang Y(2019) Evaluation of eco-efficiency in China from 1978 to 2016:based on a modified ecological footprint model. Sci Total Environ 662:581-590 

Research Journal 79:35-43

Zhao Z, Bai Y, Wang G, Chen J,Yu, J,Liu W(2018) Land eco-efficiency for new-type urbanization in the BeijingTianjin-Hebei Region. Technol Forecast Soc Change 137:19-26 province based on Super-SBM and panel regression mode 


\section{Figures}

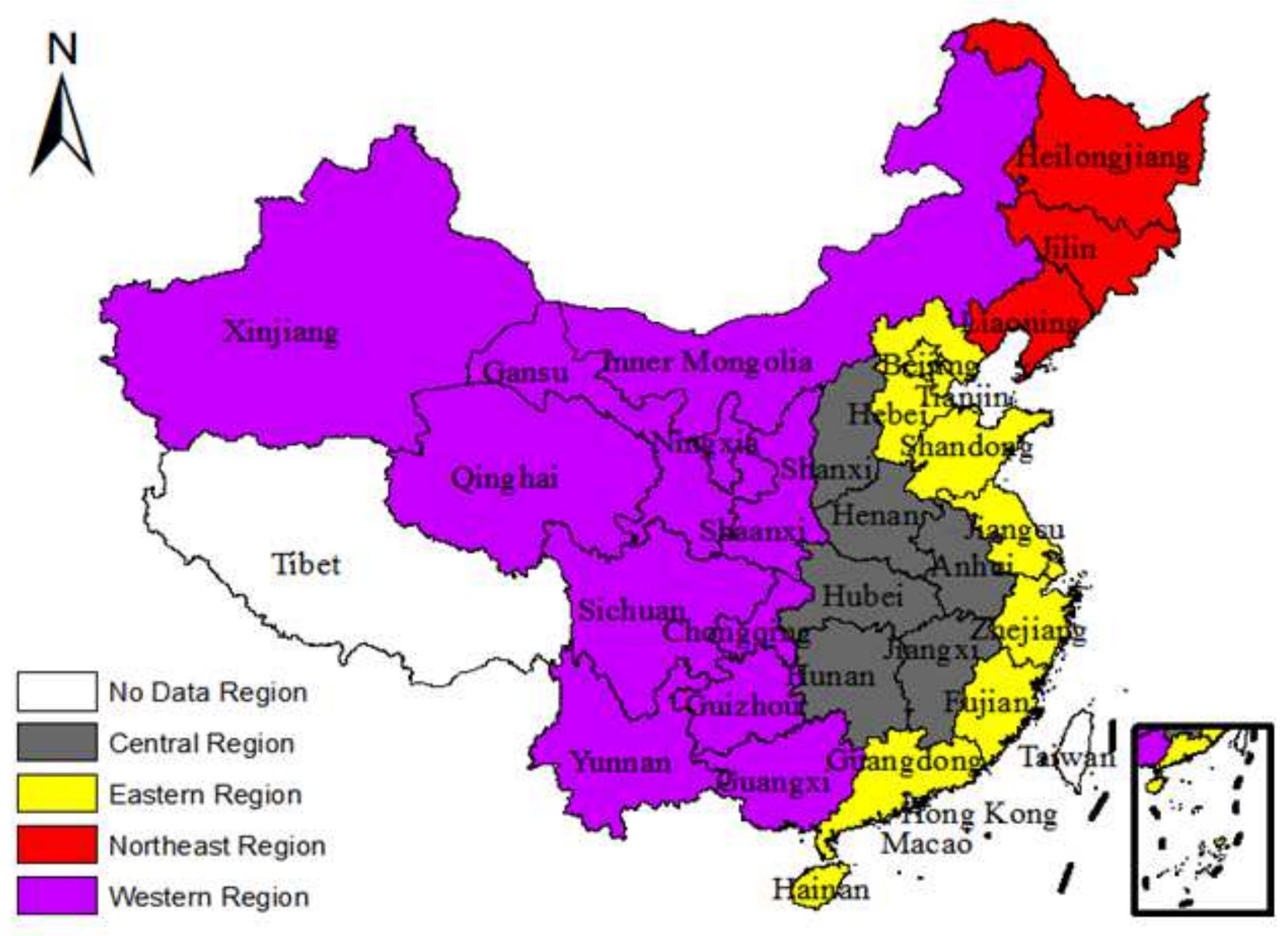

\section{Figure 1}

Four regions of China Note: The designations employed and the presentation of the material on this map do not imply the expression of any opinion whatsoever on the part of Research Square concerning the legal status of any country, territory, city or area or of its authorities, or concerning the delimitation of its frontiers or boundaries. This map has been provided by the authors. 


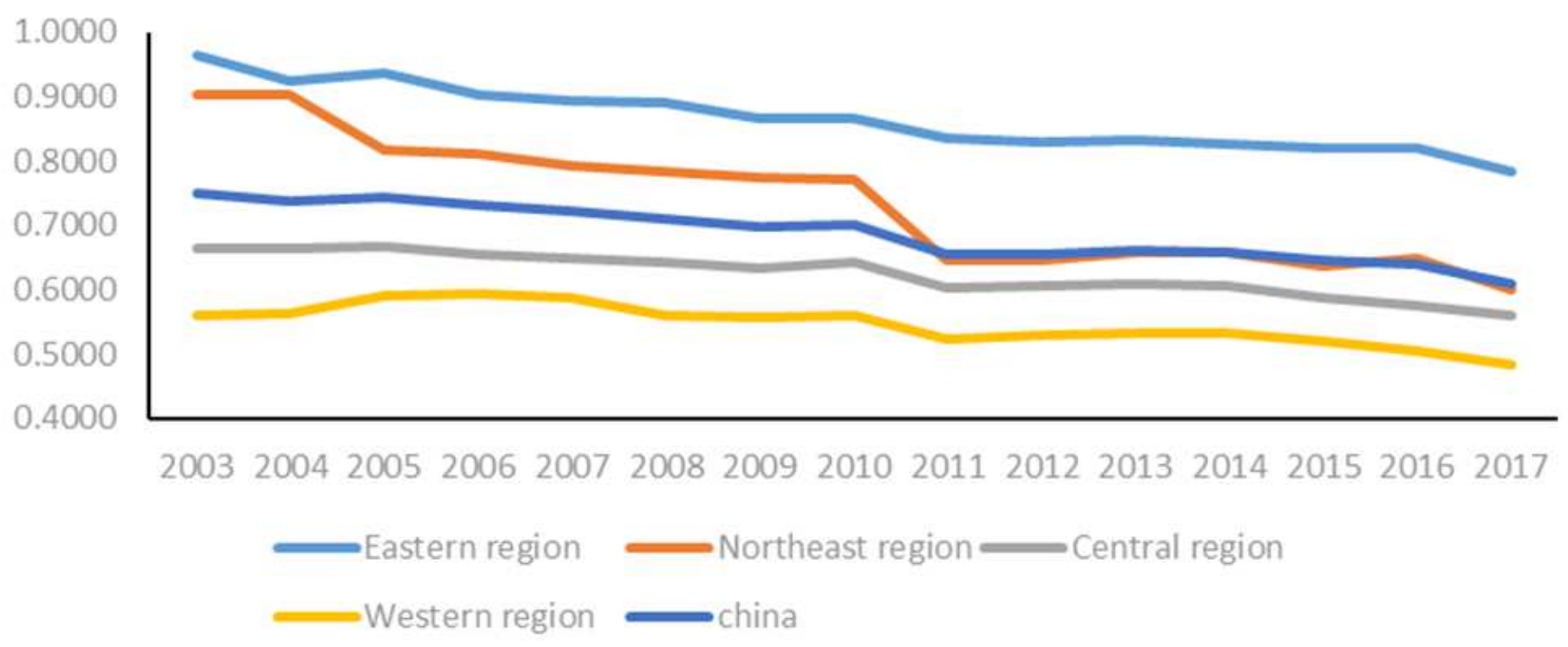

Figure 2

Development Trend of TFEE in China and the four Regions (2003-2017)

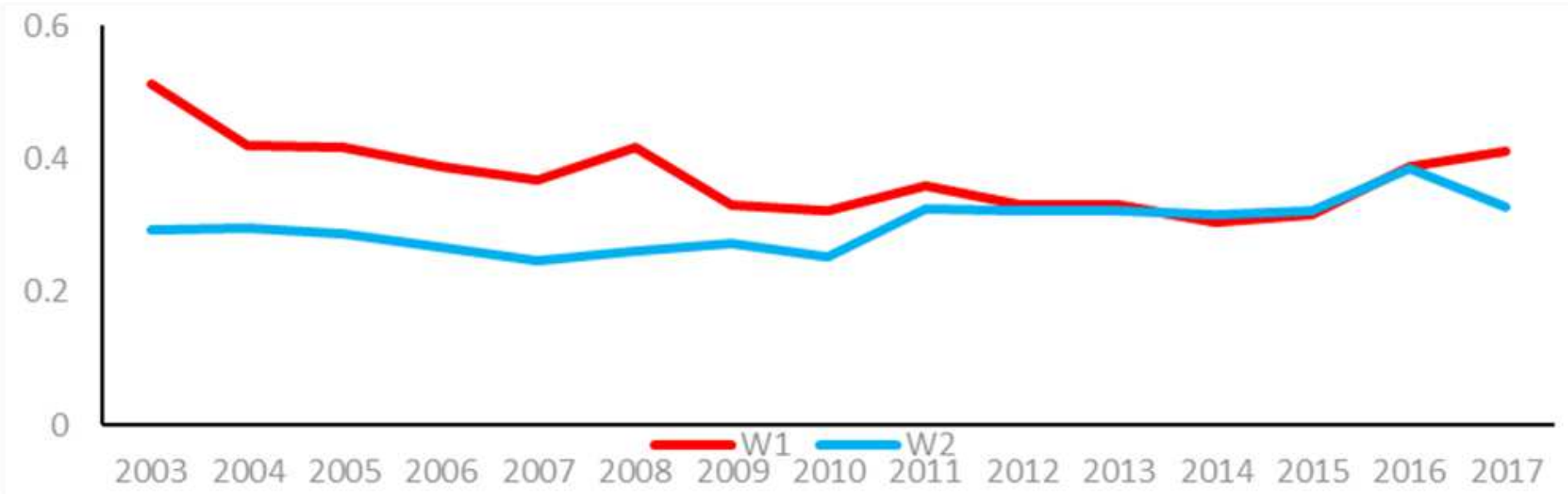

Figure 3

Development trend of Moran's I index (2003-2017) 

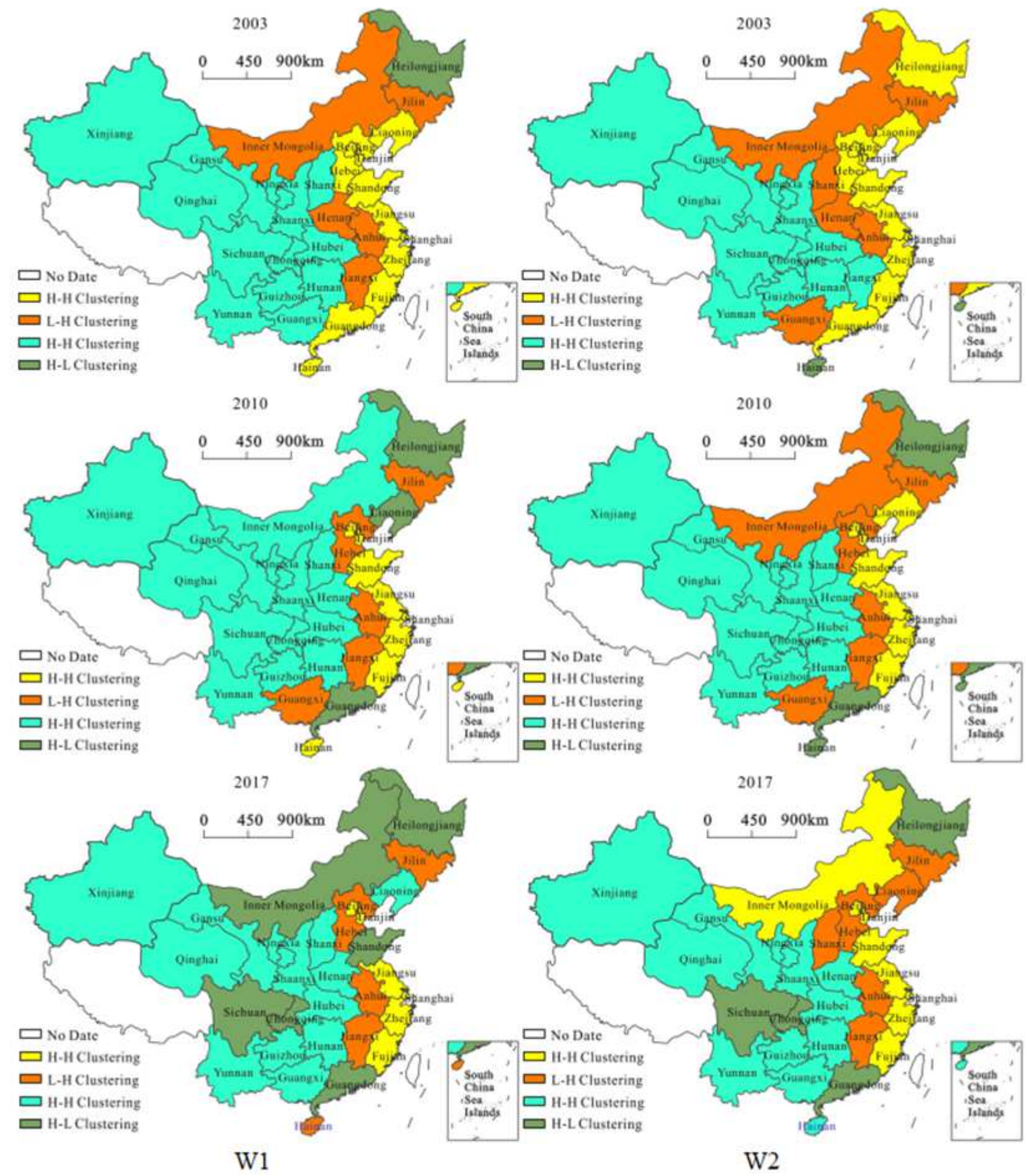

\section{Figure 4}

Chinese provincial TFEE Moran's I spatial distribution of scatter Note: The designations employed and the presentation of the material on this map do not imply the expression of any opinion whatsoever on the part of Research Square concerning the legal status of any country, territory, city or area or of its authorities, or concerning the delimitation of its frontiers or boundaries. This map has been provided by the authors. 